\title{
ANÁLISE DA VULNERABILIDADE FÍSICO-AMBIENTAL CAUSADA PELAS CHUVAS INTENSAS NA REGIÃO METROPOLITANA DE MACEIÓ
}

\author{
Melchior Carlos do Nascimento \\ Universidade Federal de Alagoas (Ufal), IGDema, Maceió, AL, Brasil \\ melchior.nascimento@igdema.ufal.br \\ Magda Adelaide Lombardo \\ Universidade Estadual Paulista (Unesp), Pós-Graduação em Geografia, Rio Claro, SP, Brasil \\ lombardo@rc.unesp.br \\ Sinval Autran Mendes Guimarães Júnior \\ Universidade Federal de Alagoas (Ufal), IGDema, Maceió, AL, Brasil \\ sinval.autran@igdema.ufal.br \\ Esdras de Lima Andrade \\ Universidade Federal de Alagoas (Ufal), IGDema, Maceió, AL, Brasil \\ esdras.andrade@igdema.ufal.br
}

\begin{abstract}
RESUMO
A ocupação irregular dos espaços urbanos têm provocado prejuízos as cidades que integram a Região Metropolitana de Maceió - RMM, comprometendo os serviços públicos como abastecimento de água, esgotamento sanitário, transporte e demais serviços essenciais à garantia da qualidade de vida. Neste sentido, o presente estudo teve como objetivo avaliar a vulnerabilidade físico-ambiental dos municípios que integram a RMM as chuvas intensas, especificamente aos problemas de deslizamento de terra e enchentes. Para tanto, adotou-se os elementos da análise sistêmica, integrando variáveis físicoambientais e antropogênicos por meio das técnicas de geoprocessamento, sendo atribuído as classes temáticas valores para determinar os diferentes níveis de vulnerabilidade aos deslizamentos de terra e enchentes. A partir das análises, foi observado que a vulnerabilidade dos municípios que integram a RMM dependem da interveniência das chuvas e da conjugação de fatores naturais e antropogênicos. A combinação entre os cartogramas físico-ambiental e antropogênico permitiu identificar que $44,12 \%$ da área de estudo possuem entre média, alta e muito alta vulnerabilidade físico-ambiental ao deslizamento de terra e que $74,17 \%$ das áreas vulneráveis as enchentes possuem entre muito baixa e baixa vulnerabilidades.
\end{abstract}

Palavras-chave: Deslizamento de terra. Enchentes Geoprocessamento. Análise Ambiental.

\section{ANALYSIS OF THE PHYSICAL-ENVIRONMENTAL VULNERABILITY CAUSEDE BY INTENSE OF THE RAINFALL IN THE METROPOLITAN REGION OF MACEIÓ}

\begin{abstract}
The irregular occupation of the urban spaces has been caused damages to the cities which are connected in the Metropolitan Region from Maceió - MRM, compromising public services as water supply, sanitary sewage, transport and also anothers essencial services to guarantee the quality of life. In this regard, the present study had as objective assess the physic-environmental vulnerability from the cities which are connected in the MRM the intense rains, specifically to the problems of lanslides and floods. For this purpose, it was adopted the elements of the systems analysis, integrating variables physic-environmental and anthropogenics by geoprocessing techniques, being assigned to the thematic areas values to determinate the different degrees of vulnerability to the lanslides and floods. From the analysis, it was observed that the vulnerability of the cities which are connected in the MRM depends of the intervening of the rains and the conjugation of natural factors and anthropogenics. The combination between the cartograms physic-environmental and anthropogenic allowed to identify that $44,12 \%$ from the area of study has between medium, high and very high vulnerability physic-environmental to the landslides and that $74,17 \%$ from vulnerable areas of the floods has between very low and low vulnerabilities.
\end{abstract}

Keywords: landslide. Flood. Geoprocessing. Environmental analysis. 


\section{INTRODUÇÃO}

O crescimento desordenado associado à falta de planejamento socialmente equânime e à adequada infraestrutura básica têm sido responsáveis pela degradação ambiental dos centros urbanos, causando impactos negativos, entre outros aspectos, nas características e dinâmicas dos solos, relevo e rios, consequentemente, potencializando os efeitos das chuvas relacionados às ocorrências de alagamento, enchentes, inundações e deslizamentos de terras. Nesse contexto, os problemas decorrentes das condições climáticas extremas têm repercutido sobremaneira na qualidade de vida das populações humanas, especialmente àquelas residentes nos ambientes urbanos.

No caso da urbanização brasileira, a sua estrutura foi marcada por um processo histórico de acumulação no qual a propriedade da terra e a exploração dos mais pobres e excluídos resultaram em espaços diferenciados com grande parte das populações urbanas vivendo em moradias precárias, com posse irregular e sem acesso a facilidades proporcionadas pelos serviços e equipamentos urbanos (SILVEIRA; BUENO, 2013, p. 1). No contexto das metrópoles brasileiras, a ocupação irregular dos espaços urbanos e a exploração indiscriminada dos recursos naturais têm provocado prejuízos ao erário, além de comprometer a qualidade dos serviços públicos como abastecimento de água, esgotamento sanitário, transporte, entre outros serviços essenciais à garantia da qualidade de vida.

Embora a estiagem prolongada possa ser considerada como principal evento climático na região Nordeste, nas regiões metropolitanas, predominam os problemas decorrentes das dinâmicas pluviométricas. Do total de 3,12 milhões de habitantes residentes no estado de Alagoas, aproximadamente $73,6 \%$ estão instalados nas áreas urbanas dos seus municípios. Embora a Região Metropolitana de Maceió (RMM) não apresente um consolidado grau de conurbação, os problemas urbanos decorrentes de eventos climáticos extremos têm ocorrido com frequência e atingido, cada vez mais, os habitantes das diversas localidades. Com uma população de aproximadamente 1,5 milhão de habitantes, os doze municípios que integram a RMM têm sido alvo de um acelerado processo de expansão urbana que, muitas vezes, acabam contrariando as condicionantes técnicas e legais.

Portanto, os estudos sobre os problemas socioambientais decorrentes das chuvas intensas, especialmente nas áreas urbanas têm recebido uma relevante contribuição das ciências humanas e sociais, principalmente da Geografia, haja vista a sua capacidade de interpretar e analisar as interações antropogênicas e naturais que atuam como fatores determinantes na composição e organização espacial. Desta maneira, torna-se essencial entender os aspectos conceituais e técnicos dos termos frequentemente utilizados, tais como risco, perigo, suscetibilidade e vulnerabilidade.

O esforço empregado para distinguir e entender os cenários que se apresentam em condições efetivas de riscos decorrentes de fatores socioculturais e aqueles que advêm da fragilidade natural do próprio ambiente têm permitido aos especialistas das diversas áreas do conhecimento reduzir as incertezas sobre a eficiência das variáveis naturais e antropogênicas passíveis de serem adotadas nas análises. Lopes (2008, p. 44) destaca que "a susceptibilidade se insere no modelo conceitual de risco, que inclui componentes como perigosidade e vulnerabilidade". De acordo com Almeida (2010, p. 540), a suscetibilidade e vulnerabilidade podem ser diferenciados como processos existenciais distintos. O referido autor considera vulnerável a pessoa intacta, mas sob o risco intrínseco de ser ferida, e suscetível como a em situação na qual efetivamente sofre por deficiência ou desvantagem, o que a predispõe a sofrer ainda dano suplementar.

Assim sendo, a simples definição que admite a suscetibilidade como algo passível de receber impressões e modificações implica abstrair a ideia de que qualquer elemento da natureza é suscetível, pois tal qualidade é determinada pelos componentes constituintes de seus atributos e a maneira como estes recebem ou reagem aos eventos de entrada - input (CHRISTOFOLETTI, 1980, p. 2). A expressão tem sua origem no latim - susceptibilitas, susceptus - e significa que alguém ou alguma coisa podem ser afetados por uma determinada ação.

Para Brasil (2007, p. 26), a suscetibilidade indica a "potencialidade de ocorrência de processos naturais e induzidos em uma dada área, expressando-se segundo classes de probabilidade de ocorrência". Julião et al (2009, p. 20) consideram que "a susceptibilidade representa a propensão para uma área ser afetada por um processo perigoso, em tempo indeterminado, sendo avaliada através dos fatores de predisposição para a ocorrência de processos ou ações, não contemplando o seu período de retorno ou a probabilidade de ocorrência".

$\begin{array}{llllll}\text { Caminhos de Geografia } & \text { Uberlândia - MG } & \text { v. 19, n. } 67 & \text { Set/2018 } & \text { p. 268-288 } & \text { Página } 269\end{array}$


Também com origem no latim - vulnerare -, a expressão vulnerabilidade, que significa ferir, penetrar, ponto pelo qual alguém ou algo pode ser atacado, tem sido tratada por algumas áreas do conhecimento como sinônimo de suscetibilidade ou risco. Um exemplo é o emprego deste termo pelas ciências da saúde, que define como vulnerabilidade grau de suscetibilidade ou de risco a que está exposta uma população de sofrer danos por um desastre natural (BIREME, 2015).

De acordo com Lima e Amaral (2013, p. 144), considera-se que o estudo elaborado por Cutter (1996) reúne um elenco variado de conceitos sobre vulnerabilidade que podem ser divididos em três diferentes categorias. A primeira, consiste na vulnerabilidade como exposição ao risco/perigo: foca na probabilidade de exposição (risco tecnológico/biofísico), categorizada como: Vulnerabilidade como condição preexistente (aqui pode ser incluída a Vulnerabilidade Natural). A segunda, denominada de vulnerabilidade como resposta social: trata da probabilidade de consequências adversas (vulnerabilidade social), categorizada como Vulnerabilidade como resposta moderada (tempered response). Por último, há a vulnerabilidade dos lugares: uma combinação das duas anteriores, categorizada como vulnerabilidade do perigo dos lugares (hazard of place - aqui pode ser englobada a ideia de Vulnerabilidade Ambiental, quando se entende que esta passa por uma perspectiva integradora de vulnerabilidade como condição preexistente e como resposta social.

Na perspectiva de Varnes (1984), as terminologias comumente utilizadas em estudo sobre desastres possuem características próprias, quando observados os elementos definidores do ambiente, sendo a maior parte delas utilizada pelos especialistas dedicados aos trabalhos relacionados a risco. Para o autor em questão, a vulnerabilidade consiste no grau de perda de um elemento em risco, em função da ocorrência de um fenômeno natural de determinada magnitude, enquanto suscetibilidade natural refere-se à probabilidade de ocorrência de um fenômeno potencialmente para destruir uma área específica.

Numa reflexão simplória sobre a diferença conceitual entre ser suscetível e estar vulnerável, é possível admitir que todos os ambientes da natureza apresentam restrições, isto é, suscetibilidades a um determinado evento, mas o grau de vulnerabilidade está diretamente condicionado ao seu estado de conservação ou preservação. Portanto, a análise da suscetibilidade remete à investigação científica para caracterização e compreensão dos limites naturais dos atributos de uma classe sob a influência de um determinado evento. Por sua vez, a vulnerabilidade exige o entendimento amplificado das condições atuais de um conjunto representativo de diferentes classes e seus respectivos atributos à possível ocorrência de um evento específico.

$\mathrm{Na}$ tentativa de exemplificar tais questões, assume-se como suscetibilidade ao deslizamento ou movimento de massa o terreno que possui em sua composição natural classes de solos situadas em uma declividade específica que, independente do estado de degradação, podem sofrer algum dano. Já a vulnerabilidade pode ser observada pelo estágio de degradação ou a simples presença da vegetação em uma encosta, que atuará como elemento determinante para a ocorrência do referido evento.

Assim sendo, embora algumas classes de solos situadas em relevo íngreme possam ser suscetíveis ao movimento de massas ou deslizamento durante os períodos chuvosos, a presença ou não de vegetação atuará como fator determinante para qualificar o grau de vulnerabilidade para que tal evento ocorra. Portanto, pode-se admitir que os terrenos que possuem em suas características condições de suscetibilidade natural e vulnerabilidade a eventos como alagamento, deslizamento, enchentes ou inundação podem ser considerados inaptos à ocupação humana, consequentemente, são ambientes de risco.

Ainda na perspectiva de reduzir possíveis ambiguidades e para melhor adequação deste estudo, considerou-se necessário detalhar os aspectos conceituais relativos aos eventos de maior ocorrência na área de estudo. Assim sendo, apesar das terminologias como suscetibilidade, vulnerabilidade, riscos, periculosidade e desastres serem utilizadas por especialistas das diferentes áreas do conhecimento humano, no presente trabalho, o emprego delas deverá sugerir a ocorrência de eventos associados apenas às chuvas intensas, tais como: alagamento, deslizamento, enchentes e inundação.

Emana desse quadro os diversos casos de alagamentos, enchentes, deslizamentos de terras e inundações frequentemente registrados por toda a RMM, que desabrigam famílias e causam vítimas fatais. As condições de vulnerabilidade da RMM às chuvas intensas, entre outros fatores, estão associadas ao processo inadequado de ocupação humana. De maneira geral, as cidades que integram a RMM já sofreram com problemas advindos das chuvas; os alagamentos, enchentes, inundações e deslizamentos de terra são os eventos mais recorrentes. 
Os municípios que integram a área de estudo possuem um histórico intensivo de intervenções que causaram mudanças consideráveis na paisagem natural, e, assim, potencializaram ainda mais os impactos das chuvas ao longo do tempo. Um exemplo desse processo consiste na lavoura da cana-deaçúcar, iniciado durante as primeiras décadas da colonização do Brasil. Essa atividade foi responsável por alterações profundas na cobertura vegetal das bacias hidrográficas, as quais provocaram, por um lado, o assoreamento e o aumento do escoamento superficial, que, por sua vez, acabam influenciando a frequência e a intensidade no histórico de ocorrência das enchentes e inundações. $\mathrm{Na}$ área de estudo, as bacias hidrográficas dos rios Mundaú e Paraíba do Meio sofreram alterações profundas em sua cobertura vegetal e já registraram verdadeiras catástrofes relacionadas às enchentes ou inundações.

Por outro lado, os efeitos provocados pelo declínio econômico da monocultura da cana-de-açúcar no estado de Alagoas alcançaram o século XXI, de modo que influenciaram a forma e a dinâmica de ocupação nas sedes administrativas dos municípios da RMM. A falta de oportunidade em suas cidades de origens favoreceu os processos migratórios para a capital e cidades circunvizinhas. Em decorrência dos valores praticados pelo mercado imobiliário, alijada do consumo e da participação econômica, a maior parte dessas famílias encontrou, nas encostas e grotões, alternativas de sobrevivência que favoreceram ainda mais a vulnerabilidade dessas áreas aos deslizamentos de terra.

Independentemente das razões que possam explicar a ocorrência de todos os eventos deflagrados pelas chuvas na RMM, é certo que os problemas a eles relacionados têm causado prejuízos diversos às populações das cidades atingidas, além de evidenciarem a incapacidade do poder público de atuar com a eficácia necessária para sua solução. Assim, é possível considerar o estudo sobre vulnerabilidade físico ambiental como um aspecto relevante na identificação dos problemas urbanos e definição de diretrizes que possam estabelecer as bases adequadas para organização do espaço geográfico, especificamente com vista à redução das situações de riscos. Portanto, as análises realizadas o presente estudo tiveram como finalidade principal determinar os condicionantes físicos da paisagem e as características predominantes de uso do solo e cobertura vegetal, capazes de evidenciar os níveis de vulnerabilidade físico ambiental da RMM a partir das enchentes e deslizamentos de terra.

\section{MATERIAIS E MÉTDOS}

\section{ASPECTOS GERAIS E LOCALIZAÇÃO DA ÁREA DE ESTUDO}

A RMM está localizada na porção central do litoral alagoano, formada pelas cidades de Barra de Santo Antônio, Barra de São Miguel, Coqueiro Seco, Maceió, Marechal Deodoro, Messias, Murici, Paripueira, Pilar, Rio Largo, Santa Luzia do Norte e Satuba (Figura 1). Embora a área total dos municípios que integram a RRM seja de aproximadamente $2.346,162 \mathrm{~km}^{2}$, os sítios urbanos consolidados estão muito aquém dessa realidade, com aproximadamente 156,961km2; as sedes dos referidos municípios ocupam apenas $6,69 \%$ da sua extensão territorial.

Situada na porção central do litoral alagoano, segundo a classificação de Thornthwaite, a RMM apresenta clima subúmido e úmido, com o período quente que se inicia geralmente em setembro e se estende até março, com temperaturas anuais em torno de $22^{\circ} \mathrm{C}$ a $28^{\circ} \mathrm{C}$. As chuvas resultam da superposição dos fatores geográficos (latitude e relevo) associados à circulação dinâmica da atmosfera, principalmente decorrentes dos alísios de SE, NE (estes com menor intensidade) e do fluxo de ar polar. Os estudos e mapeamentos realizados por Alagoas (1999) e Embrapa (2012) caracterizam a RMM como de clima do tipo úmido e subúmido úmido com as seguintes variações: B2 - Clima úmido, com índice entre 40 e 60; B1 - Clima úmido, com índice entre 20 e 40; e C2 - Clima Subúmido úmido, com índice entre 0 e 20 .

O Clima úmido ocorre nos municípios de Barra de Santo Antônio, Coqueiro Seco, Maceió, Paripueira, Pilar, Maceió, Marechal Deodoro, Rio Largo, Santa Luzia do Norte e Satuba. Nesses municípios, a quantidade de chuvas precipitadas em milímetros pela sua média anual é muito superior à Evapotranspiração Potencial ou à quantidade exigida pelas plantas para o seu crescimento e manutenção verde durante todo o ano (ASSIS et al, 2012). O Clima subúmido abrange as demais partes da RMM e parcelas dos municípios de Coqueiro Seco, Maceió, Marechal Deodoro, Pilar e Rio Largo. A média anual de chuvas também é superior à da Evapotranspiração Potencial.

A RMM apresenta dois períodos: chuvoso, entre os meses de abril, maio, junho, julho e agosto; e o outro seco, nos meses de setembro, outubro, novembro, dezembro, janeiro, fevereiro e março. $O$ período mais chuvoso do ano corresponde aos meses de maio, junho e julho; este trimestre é responsável por aproximadamente $40 \%$ a $50 \%$ do total anual da precipitação na RMM.

\begin{tabular}{llllll}
\hline Caminhos de Geografia & Uberlândia - MG & v. 19, n. 67 & Set/2018 & p. 268-288 & Página 271
\end{tabular}


Figura 1: Localização da Região Metropolitana de Maceió, Alagoas, Brasil.

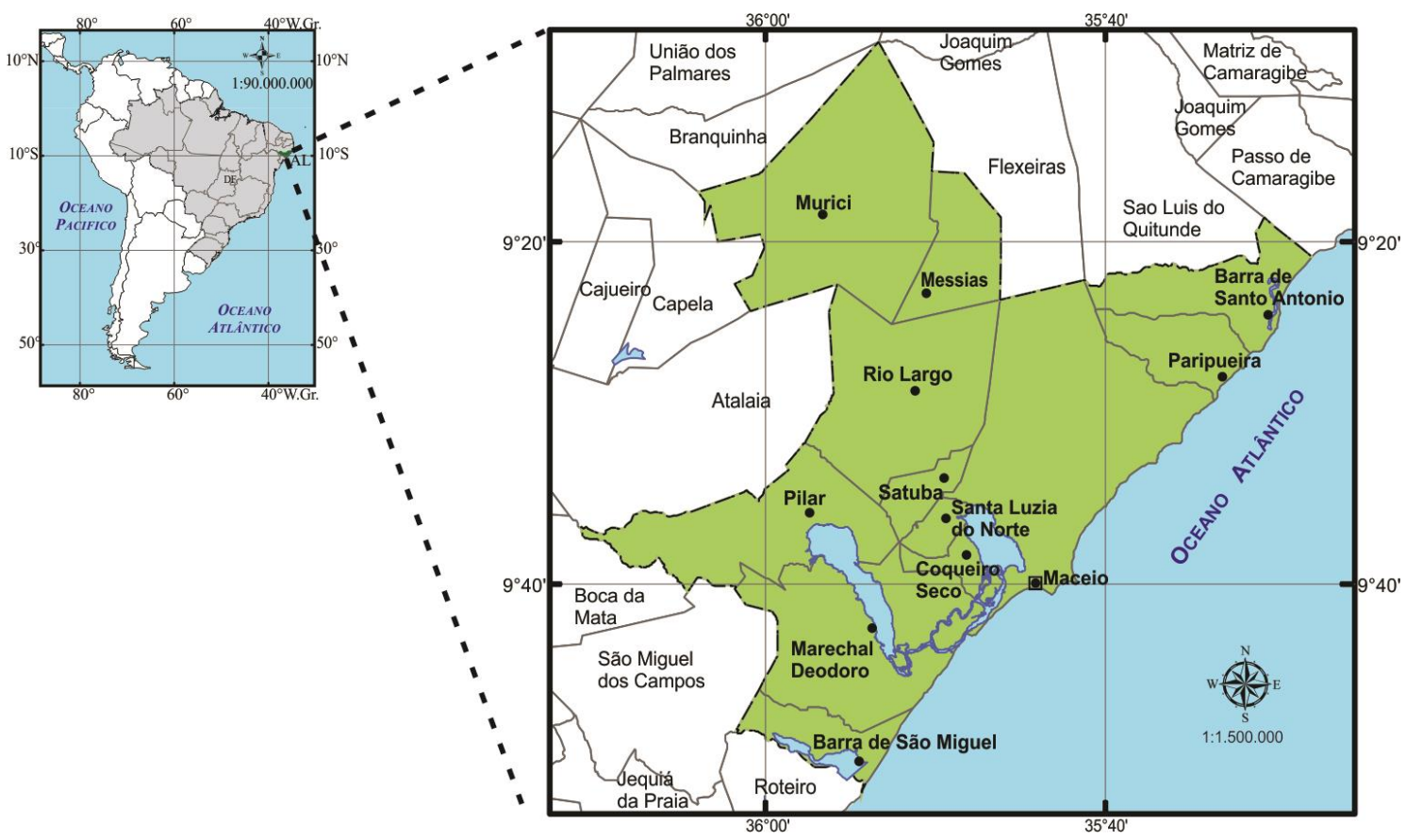

De acordo com Fonseca e Azevedo (1983), o regime pluviométrico apresenta variação mesoclimática total anual entre $1.500 \mathrm{~mm}$ a $2.000 \mathrm{~mm}$, com pluviometrias totais na média anual de $1.600 \mathrm{~mm}$; média em janeiro (verão) de aproximadamente $50 \mathrm{~mm}$; média em abril (outono) de $250 \mathrm{~mm}$; média em julho (inverno) de $200 \mathrm{~mm}$ e média em outubro (primavera) de $50 \mathrm{~mm}$. A intensidade pluviométrica obtida pela pluviosidade média anual $(\mathrm{mm})$ na duração do período chuvoso (número de meses) varia de $200 \mathrm{~mm}$ a $350 \mathrm{~mm} / \mathrm{mês}$ na região das lagunas. Na proximidade do litoral, a intensidade pluviométrica varia de $250 \mathrm{~mm}$ a $275 \mathrm{~mm} / \mathrm{mês}$, enquanto na área mais afastada do litoral, a intensidade varia de $200 \mathrm{~mm}$ a $275 \mathrm{~mm} / \mathrm{mês}$, ocorrendo em menor abrangência intensidades entre $275 \mathrm{~mm}$ a $350 \mathrm{~mm} / \mathrm{mês}$.

Do ponto de vista litológico, a RMM mostra um domínio de terrenos sedimentares, onde se encontram três unidades litológicas: os Sedimentos Quaternários de Praia e Aluvião; os Sedimentos Tércio-quaternários da Formação Barreiras, ambos contidos na Bacia Sedimentar Alagoas e Rochas Cristalinas Intrusivas Ácidas do Complexo Migmatítico-Granítico, do Maciço ou Domínio Pernambuco e Alagoas (DANTAS; CALHEIROS, 1986); e o Domo/Inlier Jirau do Ponciano, contido na Província da Borborema, Subprovíncia Meridional.

Considerando que as formas de relevo são resultantes da ação da tectônica, litologia e climas atuais e passados, os mapeamentos realizados por Nou et al (1983), do ponto de vista estrutural, são encontrados na RMM as regiões geomorfológicas da Planície Litorânea, dos Piemontes Inumados e do Planalto da Borborema. No caso da Planície Litorânea, são observadas as presenças das unidades geomorfológicas das Planícies Deltaicas, Estuarinas, Praias, Várzeas e Terraços Aluviais. Os Piemontes Inumados são marcados pela presença das unidades geomorfológicas dos Tabuleiros Costeiros, nas quais se registra a presença de Falésias, Encostas/Vales Fluviais, Topos de Interflúvios, Rampas Coluviais, entre outras. O Planalto da Borborema é marcado pela presença da unidade geomorfológica das suas Encostas Orientais, em que é observada a presença marcante de Serras, Vales ou Sulcos Estruturais, Patamares Estruturais, Linhas de Cumeadas e Pontões, entre outros.

Segundo os mapeamentos e estudos realizados por Jacomine et al (1975); Wake et al (1983); Brasil (2012), os solos mais representativos da RMM têm sua ocorrência relacionada às unidades geomorfológicas que integram as regiões da Planície Litorânea e dos Piemontes Inumados. As ocorrências nos topos dos Piemontes Inumados são caracterizadas pela presença de Latossolos Amarelos e Latossolos Acinzentados. Já nas encostas, predominam os Argissolos Amarelos, Argissolos Vermelho-Amarelos, Argissolos Acinzentados e os Neossolos Litólicos. Na Planície Litorânea ou Baixada Litorânea, ocorrem os Gleissolos Háplicos (Várzeas e Terraços Fluviais), os Espodossolos Humilúvicos (Terraços Marinhos, Flúvio-marinhos e Flúvio-marinhos lacustres), os

$\begin{array}{llllll}\text { Caminhos de Geografia } & \text { Uberlândia - MG } & \text { v. 19, n. 67 } & \text { Set/2018 } & \text { p. 268-288 } & \text { Página } 272\end{array}$


Neossolos Flúvicos (Terraços Colúvio-aluvionares e Estruturais), os Neossolos Quartzarênicos (Terraços Marinhos Holocênicos e Pleistocênicos) e os Solos Indiscriminados de Mangues (Alagadiços de Marés/Vasas Flúvio-Marinhas Lagunares).

Estudos e mapeamentos realizados por Assis $(1998 ; 1999 ; 2000)$ e mais na recentemente Alagoas (2010) revelam que as áreas de vegetação nativa da área de estudo encontram-se bastante reduzidas, restando algumas parcelas isoladas, principalmente nas encostas dos tabuleiros, nos quais estão presentes remanescentes da Floresta Ombrófila secundária (Mata de Tabuleiro e Mata Serrana) e a Savana (Cerrado). Na Planície Litorânea, são observados resquícios de Formações Pioneiras sob influência Marinha (Restingas Herbáceas) e Flúvio-marinha (Mangues).

No caso das parcelas do território suscetíveis a deslizamento, a preservação das espécies que constituem os diferentes ambientes fitogeográficos presentes na RMM tem sido um aliado importante; por isso, torna-se essencial a adoção de critérios que assegurem a proteção desses ambientes. Ademais, como alternativa para atenuar os efeitos das chuvas intensas sobre as encostas, sugere-se a preservação da vegetação nativa, bem como das espécies adaptadas a esses ambientes, as quais se desenvolveram decorrentes de um desordenado processo de ocupação. Assim sendo, as classes de uso do solo e cobertura vegetal podem ser agrupadas em dois sistemas: um antrópico e outro fitofisionômico. No caso do sistema antrópico, a sua ocorrência é resultado da interferência humana, no qual predominam as áreas agrícolas, urbanas, pastagens, entre outras classes. Já o sistema fitofisionômico consiste em áreas formadas pela significativa presença de remanescentes florestais, várzeas, campos, capoeira, entre outras ocorrências.

\section{ABORDAGEM METODOLÓGICA}

Os procedimentos metodológicos utilizados no presente estudo adotam como fundamento teórico elementos da análise sistêmica, em que é realizada a integração de variáveis físicas ambientais e antropogênicas. Desta forma, foram adotados uma série de procedimentos e técnicas complementares e inter-relacionadas, desenvolvidos em um Sistema de Informação Geográfica (SIG), no qual foi possível avaliar e selecionar as variáveis mais relevantes para definição dos variados graus de vulnerabilidade físico ambiental relacionados às chuvas intensas que influenciam decisivamente na ocorrência dos problemas associados aos deslizamentos de terras e enchentes.

Assim sendo, considerando os níveis variados de suscetibilidade que cada referido plano temático de informação pode representar, foram atribuídos os valores 1, 2, 3, 4 e 5, respectivamente, muito-baixo, baixo, médio, alto e muito-alto, para determinar diferenças entre as classes correspondentes a cada cartograma, sendo adotado o valor 0 (zero) quando essa não estiver sujeita à ocorrência do evento ou fora da análise. Tal definição foi baseada nas propriedades e características das classes mapeadas e na capacidade de interveniência das dinâmicas climáticas sobre cada uma delas. Portanto, admitiram-se os referidos valores, levando-se em conta apenas os evento relacionados aos deslizamentos de terra e enchentes.

\section{MATERIAL UTILIZADO}

A preparação e geração da base de dados espaciais, foram gerados a partir da coleta de dados convencionais e levantamentos em campo. A edição dos dados básicos e temáticos foi realizada no programa ArcGis, versão 10.1, e compreendeu o ajuste para escala de 1:50.000 das variáveis formadas pelos elementos influenciadores das características morfológicas e geoambientais, tais como a hipsometria , declividade, litoestrutura, relevo e solos. As unidades litológicas foram compiladas e adaptadas com base nos mapeamentos efetuados por Ricther et al (1975) e Dantas e Calheiros (1986). A atualização das classes seguiu a orientação taxonômica estabelecida por Feijó (1994) em estudos desenvolvidos na bacia Sergipe Alagoas. As unidades geomorfológicas foram mapeadas com base nos estudos elaborados por Goes (1979), Costa (1980), Nou et al (1983), Marques (1987) e Lima (1990). Para tanto, utilizaram-se as cartas topográficas e cartas geológicas. A partir das curvas em nível, pontos cotados, rede de drenagem e corpos d'água, obteve-se o Modelo Digitação de Elevação e, por conseguinte, as classes de altitude e declividade da área de estudo. De posse dos referidos mapas e com o auxílio dos mapas temáticos relativos à distribuição das formas de relevo, elementos litológicos, pedológicos e o uso de solo e cobertura vegetal, delimitaram-se as unidades morfológicas da RMM.

$\begin{array}{llllll}\text { Caminhos de Geografia } & \text { Uberlândia - MG } & \text { v. 19, n. } 67 & \text { Set/2018 } & \text { p. 268-288 } & \text { Página } 273\end{array}$


Para elaboração das unidades de solos, adotaram-se como referência os estudos desenvolvidos por Jacomine et al (1975), Wake et al (1983) e Embrapa (2012). Tendo em vista os objetivos delineados no presente estudo, realizou-se a extrapolação das classes de solos dos mapas elaborados pela Embrapa Solos, escala 1:100.00, correspondente ao Zoneamento Agroecológco do Estado de Alagoas. Além das condições pedológicas existentes, adotaram-se como critério os aspectos litológicos e morfológicos, já que a referida área de estudo apresenta certa homogeneidade entre essas variáveis definidoras das classes de solos. O mapa de declividade foi produzido a partir das cartas topográficas nas escalas 1:25.000 (PETROBRÁS, 1965), 1:50.000 (IBGE, 1987) e 1:100.000 (SUDENE, 1989). O shapefile correspondente às curvas em nível foi convertido para vetor do tipo ponto e unido aos pontos cotados. Em seguida, adotou-se a TIN (Triangulated Irregular Network) como algoritmo de interpolação para produção do Modelo Digital de Elevação, com resolução espacial de 10 metros.

O mapeamento das classes de uso do solo e cobertura vegetal seguiu as orientações taxonômicas dos trabalhos realizados por Veloso e Goes Filho (1982), Veloso et al (1991) e Assis (1985). Para tanto, utilizaram-se as imagens do satélite RapidEye, com resolução espacial de 5 metros, compatível com a escala 1:50.000. A identificação foi realizada a partir da análise interpretativa das referidas imagens, seguida da vetorização das classes de uso do solo e cobertura vegetal, pela qual identificou-se as ocorrências predominantes na área de estudo, capazes de influenciar os níveis de vulnerabilidade físico ambiental aos eventos relacionados aos deslizamentos e enchentes.

\section{SELEÇÃO DOS INDICADORES}

Os indicadores foram selecionados com base nas características da área de estudo, considerando-se como aspectos determinantes a facilidade de interpretação, a objetividade, a possibilidade de atualização e a capacidade para definição dos níveis de vulnerabilidade socioambiental. Essa etapa do estudo consistiu na definição dos cartogramas temáticos que permitissem correlacionar as características e condições físico-ambientais da área de estudo às diferentes formas de organização espacial. Ao se considerar a gênese, constituição física, forma e estágio de evolução como aspectos determinantes para qualificação do nível de suscetibilidade, foram definidos como variáveis do sistema físico ambiental: a litologia, geomorfologia, solos e declividade. No caso do sistema antrópico, considerou-se: a capacidade para identificar as alterações impostas pela ocupação humana e as formas dominantes de uso e ocupação do solo, sendo definido como variável o cartograma de uso do solo e cobertura vegetal. Assim, os cartogramas temáticos selecionados reuniram, em suas características, variáveis físico-ambientais e antropogênicas capazes de identificar através da integração espacial as parcelas do território mais ou menos vulneráveis aos deslizamentos de terra e enchentes.

A decisão pela utilização do cartograma de unidades litológicas foi motivada por essa variável físicoambiental ser capaz de contribuir para revelar a localização das parcelas do território mais propícias às ocorrências de deslizamentos de terra e enchentes, de forma a reduzir as dúvidas ou incertezas quando da realização das operações de álgebras de mapas. Além disso, a ação pluviométrica sobre alguns componentes geológicos pode promover efeitos físicos e químicos capazes de influenciar de maneira variada o grau de intemperismo. Por conseguinte, a desintegração mecânica ou a ação química conjugadas a outros fatores favorecem ainda mais as ocorrências de deslizamentos de terra. Portanto, buscando qualificar os diferentes níveis de vulnerabilidade a deslizamento de terra e enchente/inundação, foram atribuídos os valores para cada classe litológica mapeada, conforme descrito no Quadro 1.

Quadro 1: Escala de vulnerabilidade a deslizamento de terra e enchentes unidades litológicas e unidades geomorfológicas predominantes na RMM, Alagoas.

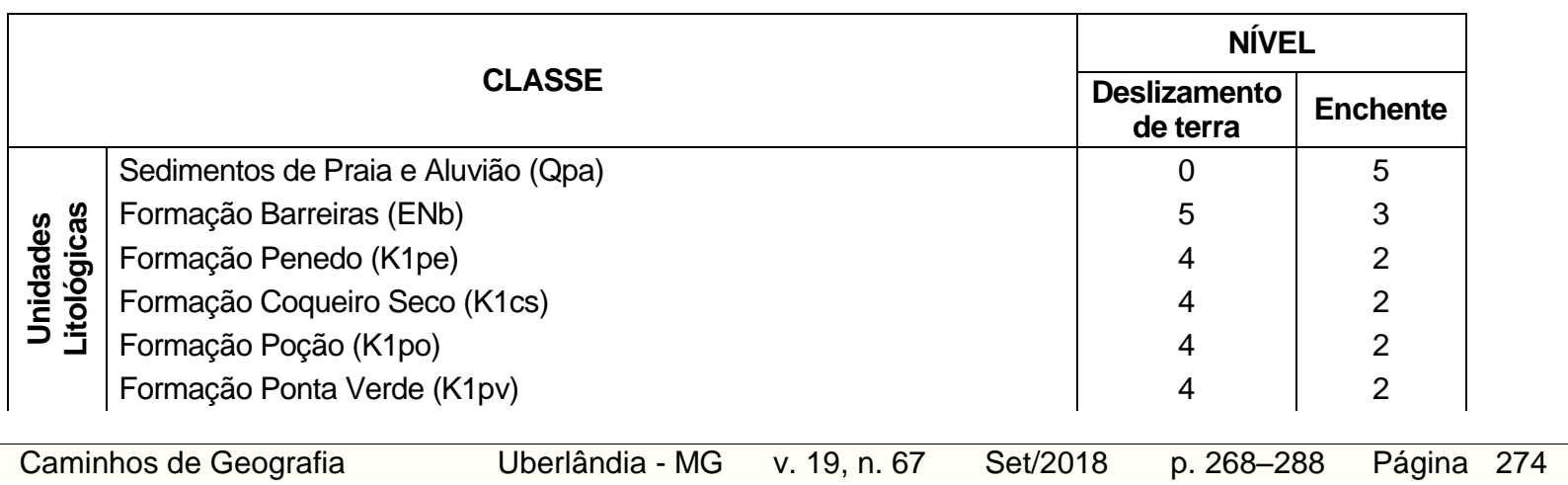




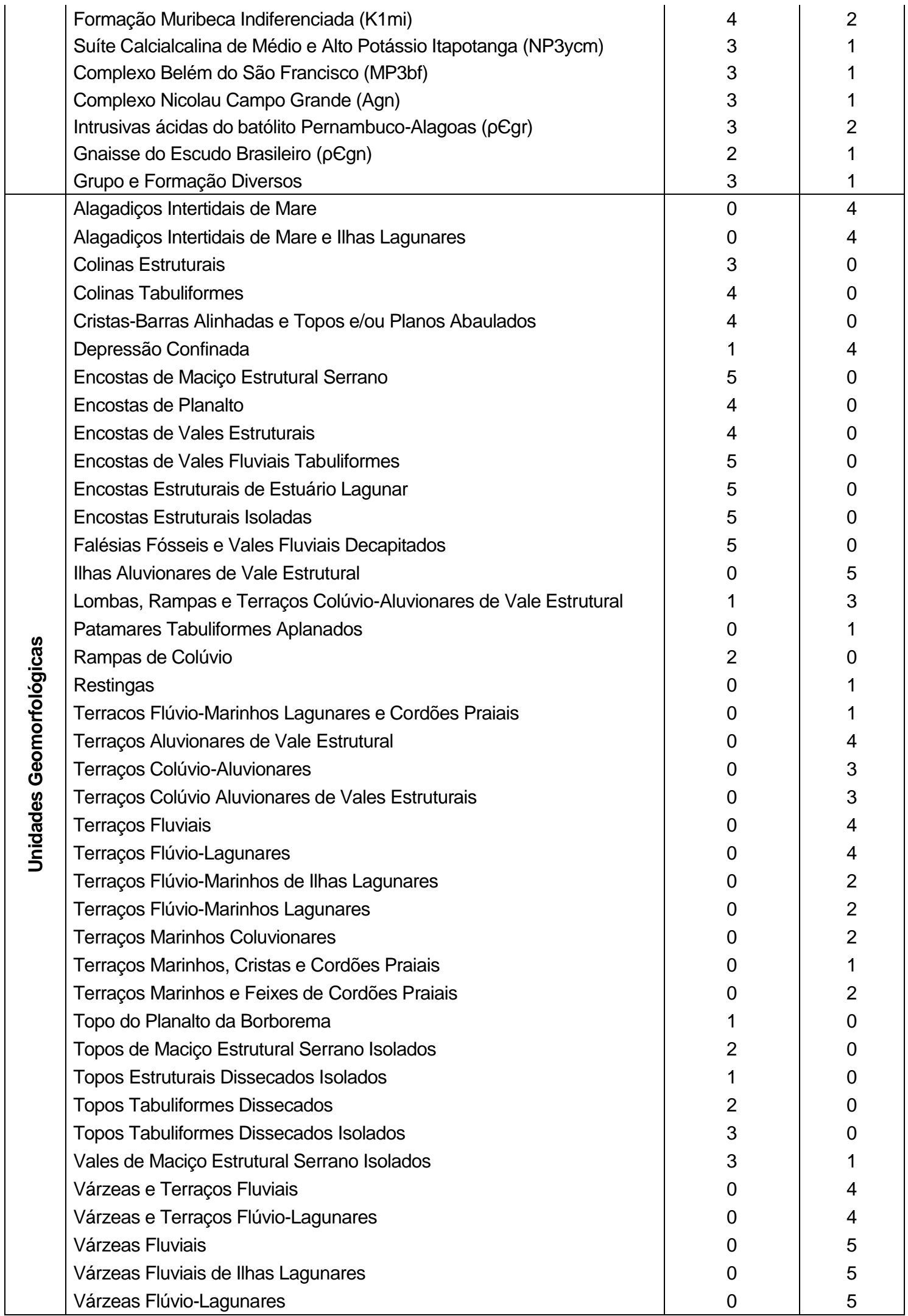

As características morfométricas do terreno, a intensidade de dissecação do relevo e a amplitude altimétrica consistem em elementos da paisagem associados à geomorfologia, capazes de revelar o grau de suscetibilidade às dinâmicas hidrológicas e pluviométricas. Por essas razões, optou-se em incluir na matriz de análise do presente estudo o plano de informação espacial correspondente às \begin{tabular}{llllll}
\hline Caminhos de Geografia & Uberlândia - MG & v. 19, n. 67 & Set/2018 & p. 268-288 & Página 275
\end{tabular} 
unidades geomorfológicas. Ross (1991, p. 13) destaca que as formas do relevo se inserem como um dos componentes de muita importância, sendo essencial para ocupação adequada do terreno o conhecimento da geomorfologia. Para facilitar as combinações dos planos de informações temáticos, as unidades geomorfológicas mapeadas foram agrupadas e qualificadas quanto a sua suscetibilidade aos processos de deslizamentos de terra e enchentes (Quadro 1).

Quadro 2: Escala de vulnerabilidade a deslizamento de terra e enchentes as classes de solos e para as faixas de declividade predominantes na RMM, Alagoas.

\begin{tabular}{|c|c|c|c|}
\hline \multirow{2}{*}{\multicolumn{2}{|c|}{ CLASSE }} & \multicolumn{2}{|c|}{ NÍVEL } \\
\hline & & Deslizamento & Enchente \\
\hline $\begin{array}{l}\text { \& } 0 \\
\frac{8}{0} \\
\frac{\pi}{0} \\
: \frac{0}{2} \\
5 \\
\end{array}$ & $\begin{array}{l}\text { Argissolos Acizentados } \\
\text { Argissolos Amarelos } \\
\text { Argissolos Vermelho-Amarelos } \\
\text { Espodossoslos Hulmilúvicos } \\
\text { Gleissolos Háplicos (GX) } \\
\text { Latossolos (LA, LA+LVA e LAC) } \\
\text { Neossolos Flúvicos (RY) } \\
\text { Neossolos Quatzarênicos (RQ) } \\
\text { Solos Indiscriminados de Mangue (SM) }\end{array}$ & $\begin{array}{l}0 \\
2 \\
4 \\
0 \\
0 \\
1 \\
0 \\
0 \\
0\end{array}$ & $\begin{array}{l}2 \\
0 \\
0 \\
3 \\
5 \\
0 \\
4 \\
1 \\
4\end{array}$ \\
\hline 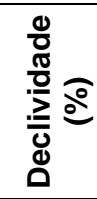 & $\begin{array}{c}<2 \\
2 \text { a } 6 \\
6 \text { a } 20 \\
20 \text { a } 50 \\
>50\end{array}$ & $\begin{array}{l}1 \\
2 \\
3 \\
4 \\
5\end{array}$ & $\begin{array}{l}5 \\
5 \\
3 \\
1 \\
0\end{array}$ \\
\hline
\end{tabular}

Por representar uma componente suscetível às precipitações pluviométricas e dinâmicas hidrológicas, as unidades de solos foram selecionadas como relevante variável físico-ambiental útil à análise da vulnerabilidade aos deslizamentos de terra e enchentes. De acordo com Resende et al (2002, p. 145), as características do relevo estão intimamente ligadas aos processos pedogenéticos, que, por sua vez, podem ser implicitamente representados pelas diversas classes de solos distribuídas na paisagem. Crepani et al (2001, p. 82) destacam que a causa fundamental da erosão hídrica, seja laminar, em sulcos ou ravinas, é a ação da chuva sobre o solo. Para esses autores, a menor ou maior suscetibilidade de um solo sofrer os processos erosivos da morfogênese depende da sua estrutura, tipo e quantidade das argilas, permeabilidade e profundidade do solo e a presença das camadas impermeáveis. Com bases nessas considerações e na forma de distribuição e ocorrência dos solos na área de estudo, atribuíram-se os valores descritos no Quadro 2.

As faixas de declividade desempenham uma função decisiva na avaliação da vulnerabilidade da paisagem aos deslizamentos de terra e enchente/inundação. De acordo com Crepani et al (2001, p. 75), quanto maior a declividade, mais rapidamente a energia potencial das águas pluviais transformase em energia cinética e maior é, também, a velocidade das massas de água e sua capacidade de transporte. Ao contrário disso, os terrenos de menor declividade consistem em ambientes de acumulação, isto é, áreas sujeitas às dinâmicas hidrológicas. Dessa maneira, as faixas de declividade também descritas no Quadro 2 basearam-se no estudo desenvolvido por Crepani et al (2001) admitiram tais intervalos de declividade apropriados para as escalas igual ou maior que 1:100.000.

A atribuição de valores qualificando as classes pertencentes ao mapa de uso do solo e cobertura vegetal considerou como critério a alteração na composição e diversidade da vegetação, em geral capaz de influenciar na compactação dos solos e nos processos erosivos, consequentemente, nas dinâmicas pluviométricas e hidrológicas. Troppmair (1988) ressalta que as alterações no meio ambiente, seja pelo desmatamento seja pelas alterações no solo, aumentam o fluxo de energia e matéria. Tal fato pode contribuir decisivamente para a ocorrência de deslizamentos de terra e enchentes. Assim sendo, a cobertura vegetal desempenha papel importante como ação protetora no tocante à perda de solos (MEDEIROS et al, 2012, p. 482). Além dos aspectos relacionados ao volume de vegetação na paisagem, também foram consideradas como fator essencial para qualificação da

$\begin{array}{llllll}\text { Caminhos de Geografia } & \text { Uberlândia - MG } & \text { v. 19, n. } 67 & \text { Set/2018 } & \text { p. 268-288 } & \text { Página } 276\end{array}$


vulnerabilidade às ocorrências de deslizamentos de terra e enchentes as classes de uso do solos e cobertura vegetal indicadoras da presença direta e indireta do ser humano na paisagem. Portanto, as áreas edificadas (áreas e sítios urbanos) e as áreas agrícolas possuem tal característica, isto é, ambas resultam da presença e intervenção direta do ser humano na paisagem, por conseguinte, receberam os maiores valores (Quadro 3). Para o caso, atribuiu-se o valor 5 (cinco) à classe denominada de área edificada por essa produzir alterações profundas na paisagem e por representar uma situação de risco quando da ocorrência de deslizamento de terra ou enchentes.

Quadro 3: Escala de vulnerabilidade a deslizamento de terra e enchentes para as classes de uso solo e cobertura vegetal predominantes na RMM, Alagoas.

\begin{tabular}{|c|c|c|c|}
\hline \multirow{2}{*}{\multicolumn{2}{|c|}{ CLASSE }} & \multicolumn{2}{|c|}{ NÍVEL } \\
\hline & & Deslizamento & Enchente \\
\hline 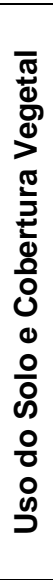 & $\begin{array}{l}\text { Área edificada } \\
\text { Lavoura de Cana-de-Açúcar } \\
\text { Lavoura de subsistência } \\
\text { Lavoura de coco-da-baía } \\
\text { Capoeira } \\
\text { Campo Sujo } \\
\text { Formação Rochosa } \\
\text { Remanescentes de floresta ombrófila (Fo) } \\
\text { Pastagem } \\
\text { Solo exposto } \\
\text { Vegetações pioneiras fluviais }(\mathrm{Pa}) \\
\text { Vegetações pioneiras flúvio-marinhas }(\mathrm{Pfm}) \\
\text { Vegetações pioneiras marinhas }(\mathrm{Pm}) \\
\text { Praias oceânicas }\end{array}$ & $\begin{array}{l}5 \\
3 \\
3 \\
3 \\
3 \\
2 \\
1 \\
1 \\
2 \\
3 \\
0 \\
0 \\
0 \\
0\end{array}$ & $\begin{array}{l}5 \\
3 \\
3 \\
3 \\
0 \\
0 \\
2 \\
1 \\
0 \\
2 \\
3 \\
5 \\
3 \\
0 \\
0\end{array}$ \\
\hline
\end{tabular}

\section{TRATAMENTO E ANÁLISE PARA APRESENTAÇÃO DOS RESULTADOS}

Os planos de informações temáticos foram tratados determinando-se suas áreas, com a utilização de planimétricas digitais, cujos dados foram expressos em forma de figuras e tabelas, contendo números absolutos e percentuais. A base de dados cartográfica utilizada para elaboração dos mapas foi projetada no sistema de coordenadas geográficas, no qual adotou-se como referência o sistema SIRGAS 2000. Assim sendo, a conjugação de todas as informações gráficas e tabelas tornaram possíveis a análise sistêmica dos municípios que integram a RMM.

\section{RESULTADOS E DISCUSSÕES}

Os municípios que integram a área estudada estão sujeitos aos problemas decorrentes das chuvas intensas, sendo estes potencializados pela forma inadequada de uso do solo e cobertura vegetal, quer seja em áreas rurais quer sejam urbanas. Assim como as demais cidades brasileiras, a região em questão também tem sido alvo de um desordenado processo de crescimento urbano que causa conflitos sobre os aspectos ambientais, legais e sociais.

Assim sendo, são encontradas diferentes formas de uso do solo; algumas delas foram introduzidas ainda durante a colonização portuguesa a partir do século XVII, como é o caso da lavoura da canade-açúcar e da atividade pecuária (ANDRADE, 2010), as quais, posteriormente, junto ao coco-dabaía, foram responsáveis pela supressão de parcelas significativas dos remanescentes de floresta ombrófila, cerrados, vegetações pioneiras fluviais, flúvio-marinhas e marinhas.

As atividades agropecuárias ainda continuam sendo responsáveis pelas principais alterações na paisagem da área de estudo, especialmente a lavoura de cana-de-açúcar e a pecuária bovina. Embora essas atividades agropecuárias tenham sido iniciadas no século XVII, a sua presença no estado de Alagoas e na própria RMM revelam um perfil socioeconômico de um passado colonial. Desta maneira, a partir das imagens do satélite RapidEye, obtidas em janeiro de 2011 , e os

$\begin{array}{llllll}\text { Caminhos de Geografia } & \text { Uberlândia - MG } & \text { v. 19, n. } 67 & \text { Set/2018 } & \text { p. 268-288 } & \text { Página } 277\end{array}$


levantamentos de campo permitiram identificar e mapear 17 (dezessete) classes de uso do solo predominantes na RMM.

Observando a Tabela 1 é possível verificar que a cana-de-açúcar e pastagem foram as classes de maiores ocorrências na área de estudo, com $918,89 \mathrm{~km}^{2}$ e $444,96 \mathrm{~km}^{2}$, respectivamente. Juntas, essas classes ocupam aproximadamente $57,91 \%$ da RMM, reforçando a influência econômica e os intensos processos antrópicos aos quais têm sido submetidas.

No que se refere à suscetibilidade das classes de uso do solo à precipitação pluviométrica, especificamente as ocorrências de deslizamento de terra e enchentes/inundação, a maior preocupação recai sobre as parcelas da área de estudo com a presença humana e/ou ocupadas por alguma atividade antrópica. Nesse caso, destacam-se as áreas edificadas, cana-de-açúcar, coco-dabaía, mineração, pastagens e reflorestamento. Portanto, considerou-se a escala de valores de 0 a 5 atribuídos no presente estudo, no qual 0 (zero) correspondente às classes não sujeitas aos eventos ou fora da análise, e os valores 1, 2, 3, 4 e 5, para determinar diferenças de vulnerabilidade, respectivamente, muito-baixo, baixo, médio, alto e muito-alto.

Tabela 1: Classes de uso do solo e cobertura vegetal identificadas a partir das imagens RapidEye na Região Metropolitana de Maceió, Alagoas, Brasil.

\begin{tabular}{c|l|c|c}
\hline \multirow{2}{*}{ ITEM } & \multicolumn{1}{|c|}{ USO DO SOLO E COBERTURA VEGETAL } & \multicolumn{2}{|c}{ ÁREA } \\
\cline { 3 - 4 } & & 160,83 & $\%$ \\
\hline 1 & Área edificada & 96,43 & 4,83 \\
2 & Campo Sujo & 918,89 & 39,02 \\
3 & Cana-de-açúcar & 18,53 & 0,79 \\
4 & Capoeira & 29,76 & 1,26 \\
5 & Coco-da-baía & 104,10 & 1,26 \\
6 & Corpos d'água & 2,90 & 0,12 \\
7 & Formação arenosa & 77,42 & 3,29 \\
8 & Vegetação Pioneira Fluvial & 26,07 & 1,11 \\
9 & Vegetação Pioneira Flúvio-marinha & 1,24 & 0,05 \\
10 & Formação Rochosa & 6,42 & 0,27 \\
11 & Lavoura de subsistência & 444,96 & 18,89 \\
12 & Pastagem & 0,65 & 0,03 \\
13 & Poços de Petróleo & 2,88 & 0,12 \\
14 & Praia & 0,11 & 0,00 \\
15 & Reflorestamento & 407,77 & 17,31 \\
16 & Remanescente florestal & 56,25 & 2,39 \\
\hline 17 & Solo exposto & $\mathbf{2 . 3 5 5 , 2 0}$ & $\mathbf{1 0 0 , 0 0}$ \\
\hline
\end{tabular}

Observando-se a Figura 2 a seguir, pode-se verificar nas classes mapeadas de uso do solo e cobertura vegetal, quanto às possíveis ocorrências de deslizamento de terra e enchentes, que a maior parte da RMM está ocupada por classes consideradas no presente estudo com média vulnerabilidade. Nesse caso, conforme descrito na Tabela 1, destacam-se as classes denominadas cana-de-açúcar $(918,89 \mathrm{~km} 2)$, coco-da-baía $(29,76 \mathrm{~km} 2)$ e os remanescentes florestais $(407,77 \mathrm{~km} 2)$ ocupando as maiores extensões de terra.

As atividades agropecuárias são responsáveis pelas principais alterações na paisagem; os setores censitários tipificados como rurais representam 5,32\% (72 unidades) do efetivo total mapeado pelo IBGE (2010), mas a extensão de terras ocupadas por esse tipo de setor censitário corresponde a aproximadamente $84,85 \%(1.998,47 \mathrm{~km} 2)$ da área de estudo.

\begin{tabular}{llllll}
\hline Caminhos de Geografia & Uberlândia - MG & v. 19, n. 67 & Set/2018 & p. 268-288 & Página 278
\end{tabular}


Figura 2: Percentual das faixas de vulnerabilidades das classes de uso do solo da RMM

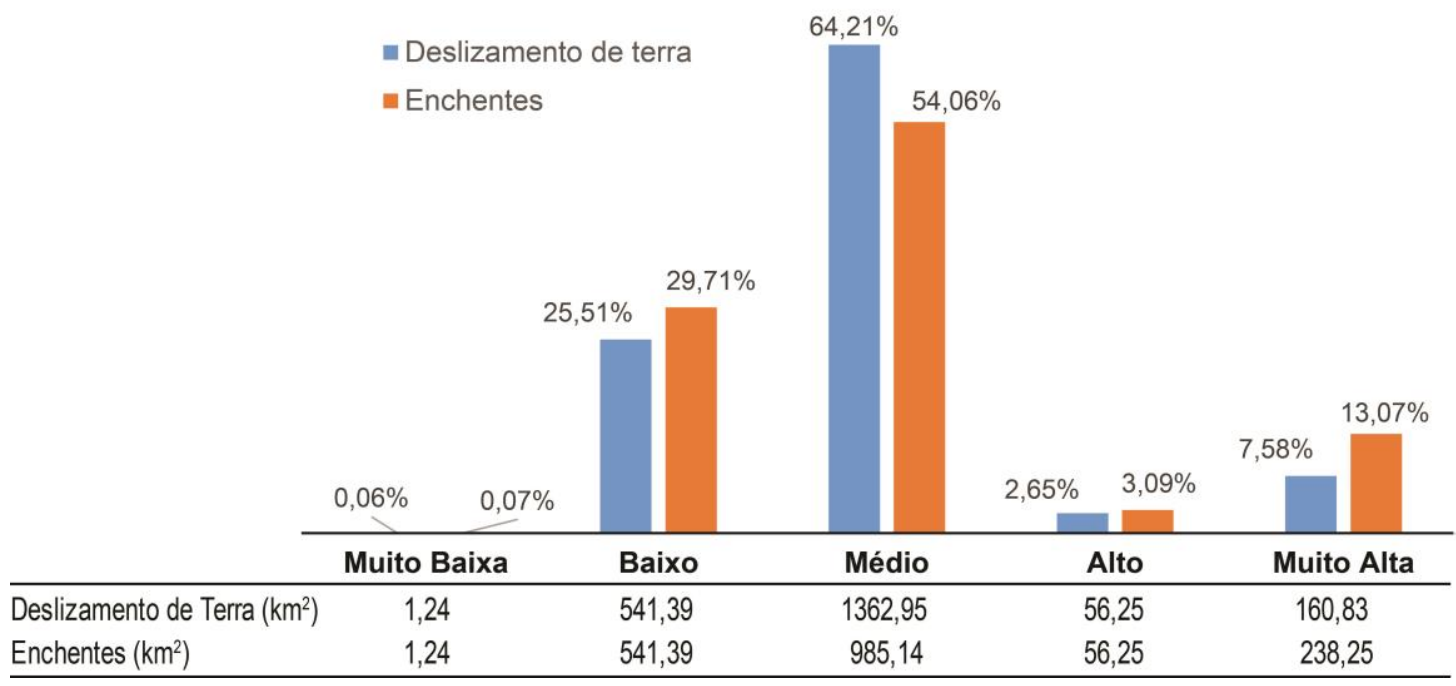

\section{VULNERABILIDADE FÍSICO-AMBIENTAL A DESLIZAMENTOS DE TERRA}

Os deslizamentos de terra se constituem em um processo erosivo que induz diretamente 0 desprendimento do solo das altas e médias encostas desprovidas de cobertura vegetal ou ocupadas de forma indevida. Em geral, esse tipo de evento está associado à interação da precipitação pluviométrica sobre os fatores físicos, ambientais e antropogênicos, que se distribuem de maneira espacialmente variada no terreno (Figura 3). Por isso, a maior ou menor possibilidade de ocorrência depende basicamente das características fisiográficas e do grau de perturbação promovido pela sociedade.

Portanto, pela análise da Figura 4 a seguir, é possível verificar que a participação percentual das classes que integram os planos temáticos de informações (PTI) usados no presente estudo por faixas de vulnerabilidade físico-ambiental ocorrem de forma variada. As classes que integram os planos temáticos de informações considerados como muito baixa (nível 1) vulnerabilidade correspondeu a um percentual de $26,18 \%$. Dentre os planos temáticos de informações utilizados, a declividade concentrou a classe com maior extensão de ocorrência na RMM; em torno de $1.183,32 \mathrm{~km}^{2}$, foram consideradas áreas com muito baixa vulnerabilidade a deslizamento de terra. Esses resultados corroboram os estudos realizados por Nou et al (1983), que identificaram os ambientes com tendência à instabilidade de dinâmica fraca como o mais abrangente na RMM.

Já as classes inseridas nas faixas muito alta (nível 5) representam a segunda maior participação em termos percentuais, ou seja, em torno de $22,66 \%$ da extensão da área de estudo. Nesse caso, as classes pertencentes aos planos de informações litológicas $\left(1.415,68 \mathrm{~km}^{2}\right)$ e geomorfológicas $\left(520,50 \mathrm{~km}^{2}\right)$ ocupam as maiores extensões na faixa de vulnerabilidade considerada muito alta (Figura 4).

Na Figura 5 é possível constatar a participação percentual dos planos temáticos de informações entre as faixas de vulnerabilidade físico-ambiental aos eventos relacionados aos deslizamentos de terras. A geomorfologia e a declividade são as únicas presentes em todas as faixas: muita baixa, baixa, média, alta e muita alta.

No que se refere à faixa considerada muito baixa, os Planos de Informação Temática (PIT) relativos à declividade, solos e uso do solo e cobertura vegetal, respectivamente, com 50,24\%, 35,37\% e $17,11 \%$ foram os que mais contribuíram para composição dessa faixa de vulnerabilidade físicoambiental. Já o PTI correspondente à geomorfologia representou $3,43 \%$ na composição dessa faixa, e as unidades litológicas não registraram nenhuma contribuição para tal evento.

$\begin{array}{llllll}\text { Caminhos de Geografia } & \text { Uberlândia - MG } & \text { v. 19, n. } 67 & \text { Set/2018 } & \text { p. 268-288 } & \text { Página } 279\end{array}$


Figura 3: Distribuição espacial das áreas com vulnerabilidade físico-ambiental a deslizamento de terra na RMM, Alagoas, Brasil.

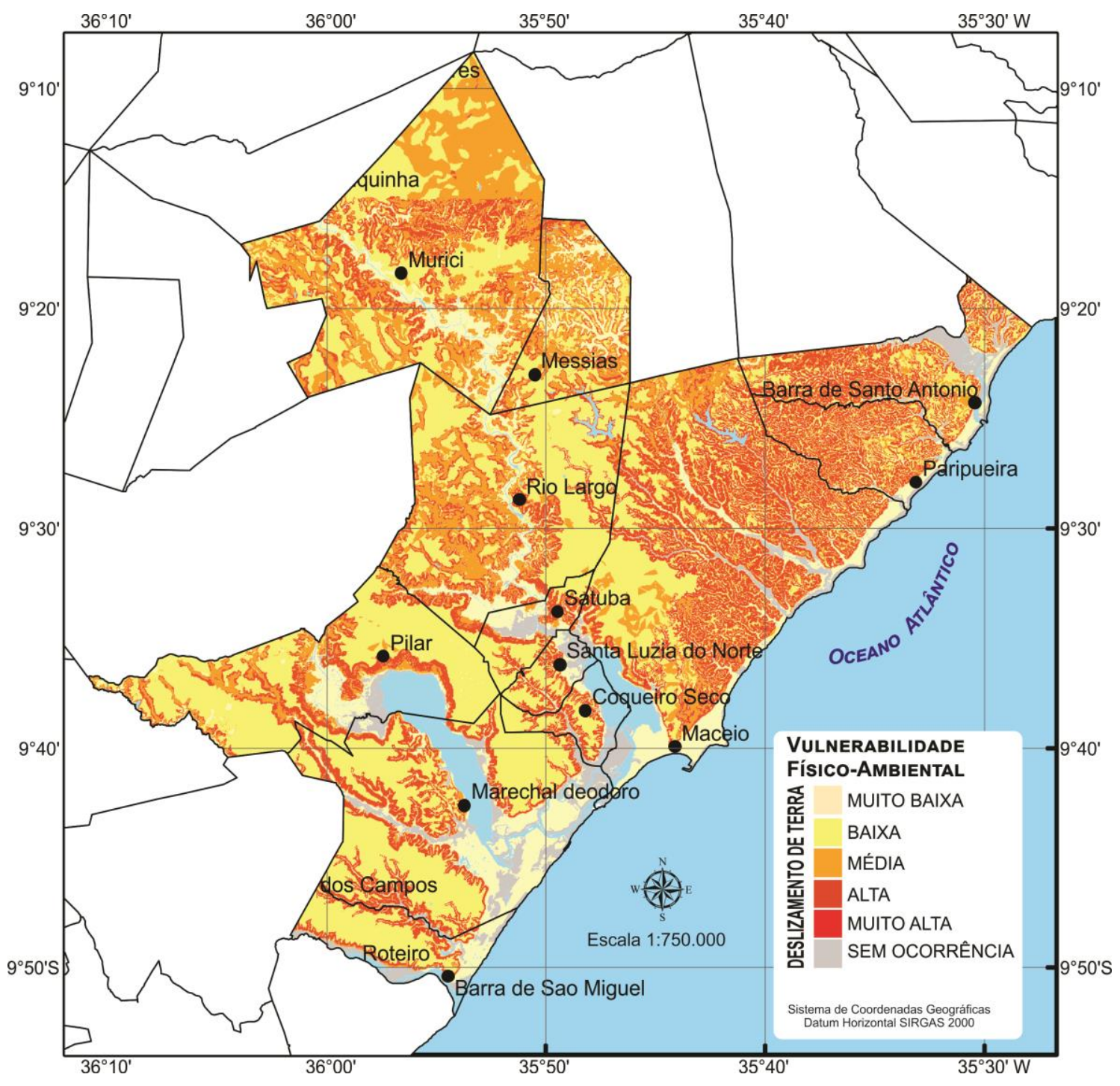

Em se tratando das faixas de vulnerabilidades baixa $(22,62 \%)$ e média $(43,18 \%)$, as classes que integram a variável uso do solo e cobertura vegetal foram aquelas que mais contribuíram no somatório para composição dessas duas faixas, ambas seguidas da declividade (Figura 5). As faixas de alta e muito alta vulnerabilidades ao deslizamento de terra tiveram como principais contributivos para sua composição o conjunto de classes que integram as unidades de litológicas $(60,11 \%)$ e de solos (39,79\%).

A integração dos referidos planos de informações temáticas permitiu identificar as áreas vulneráveis aos deslizamentos de terra na RMM (Figura 5). A Tabela 2 a seguir mostra, por um lado, que a maior parte da área de estudo possui baixa vulnerabilidade físico-ambiental a deslizamento de terra $\left(856,92 \mathrm{~km}^{2}\right)$, aproximadamente $36,38 \%$ de sua extensão territorial. Por outro lado, as áreas consideradas com muito alta vulnerabilidade representam apenas $0,42 \%\left(9,81 \mathrm{~km}^{2}\right)$ da RMM e estão concentradas, em sua maior parte, na cidade de Maceió. 
Figura 4: Percentuais das áreas ocupadas pelas classes por faixa de vulnerabilidade a deslizamento de terra.

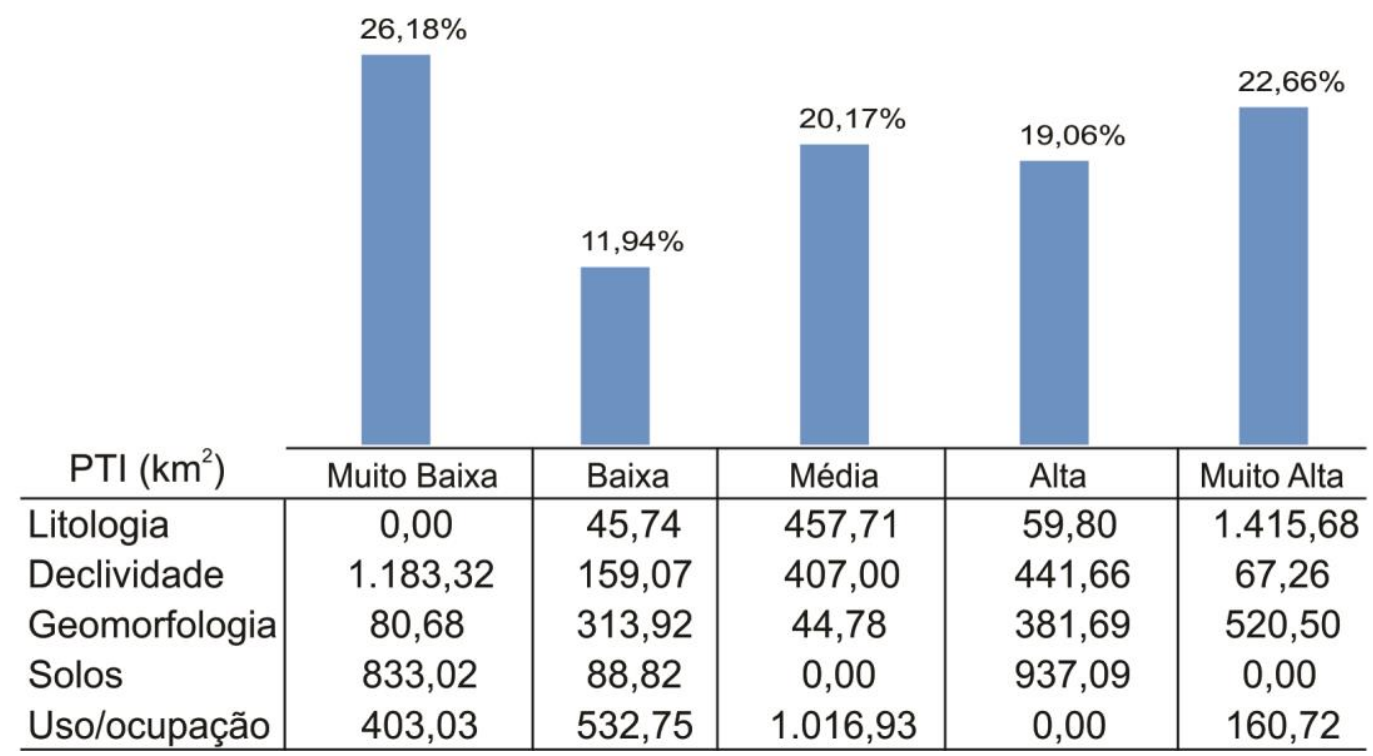

Figura 5: Distribuição percentual por faixa de vulnerabilidade a deslizamento de terra das classes pertencentes aos PTI físico-ambiental e socioeconômico.
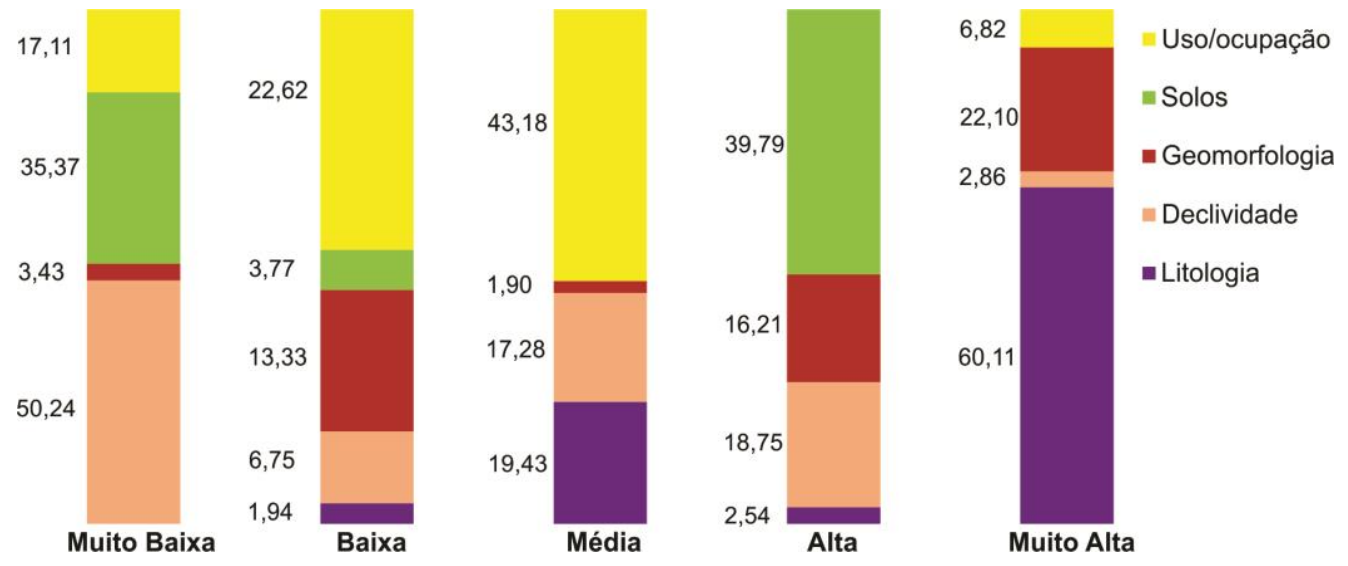

Ainda observando a Tabela 2, é possível verificar que a maior parte da RMM é formada por áreas consideradas entre muito baixa a média vulnerabilidades ao deslizamento de terra, sendo o somatório delas equivalente a $64,78 \%$ da referida área de estudo. De acordo com a integração dos planos temáticos de informações usados no presente estudo, as áreas consideradas com alta vulnerabilidade aos problemas de deslizamento de terra ocupam uma extensão de $591,04 \mathrm{~km}^{2}$, isto é, aproximadamente $1 / 4(25 \%)$ da RMM.

De maneira geral, a maior parte da RMM possui baixa vulnerabilidade a deslizamento de terra, mas, se observados os resultados isoladamente, por município, é possível verificar que em algumas cidades predominam as áreas consideradas de alta vulnerabilidade. Tal fato pode ser constatado pela análise da Tabela 3 a seguir, em que se verificou que nos municípios metropolitanos da Barra de Santo Antônio $\left(76,99 \mathrm{~km}^{2}\right)$, Maceió $\left(186,96 \mathrm{~km}^{2}\right)$ e Paripueira $\left(65,94 \mathrm{~km}^{2}\right)$ predominam as áreas com alta vulnerabilidade. Embora esses municípios tenham em seus históricos de ocorrências problemas variados relacionados às chuvas intensas, observou-se durante as incursões em campo que os mais frequentes estão associados aos deslizamentos de terra. 
Tabela 2:1 Faixas de vulnerabilidade físico-ambiental ao deslizamento de terra da RMM

\begin{tabular}{lcc}
\hline Vulnerabilidade a deslizamento de terra & $\mathrm{km}^{2}$ & $\%$ \\
\hline Sem Ocorrência & 228,55 & 9,70 \\
Muito Baixa & 230,60 & 9,79 \\
Baixa & 856,92 & 36,38 \\
Média & 438,28 & 18,61 \\
Alta & 591,04 & 25,09 \\
Muito Alta & 9,81 & 0,42 \\
TOTAL & $2.355,20$ & 100,00 \\
\hline
\end{tabular}

Tabela 3: Área total das faixas de vulnerabilidade físico-ambiental ao deslizamento de terra entre os municípios que integram a RMM, Alagoas, Brasil.

\begin{tabular}{l|c|c|c|c|c}
\hline \multirow{2}{*}{ Município } & \multicolumn{5}{|c}{ Área $\left(\mathrm{km}^{2}\right)$} \\
\cline { 2 - 6 } & Muito Baixa & Baixa & Média & Alta & Muito Alta \\
\hline Barra de Santo Antônio & 10,35 & 34,57 & 16,57 & 53,36 & 0,13 \\
Barra de São Miguel & 9,03 & 34,74 & 2,17 & 13,72 & 0,02 \\
Coqueiro Seco & 3,72 & 19,39 & 6,87 & 9,03 & 0,05 \\
Maceió & 47,43 & 137,32 & 73,41 & 186,96 & 8,97 \\
Marechal Deodoro & 48,88 & 135,93 & 8,20 & 65,94 & 0,07 \\
Messias & 17,82 & 32,12 & 43,12 & 19,26 & 0,04 \\
Murici & 33,30 & 142,80 & 169,27 & 76,99 & 0,00 \\
Paripueira & 8,32 & 22,036 & 11,519 & 46,19 & 0,22 \\
Pilar & 18,80 & 134,87 & 30,42 & 39,11 & 0,02 \\
Rio Largo & 23,38 & 139,13 & 74,29 & 61,46 & 0,04 \\
Santa Luzia do Norte & 3,81 & 9,88 & 0,67 & 10,24 & 0,04 \\
Satuba & 5,74 & 14,15 & 1,78 & 8,762 & 0,19 \\
\hline
\end{tabular}

\section{VULNERABILIDADE FÍSICO-AMBIENTAL À ENCHENTE/INUNDAÇÃO}

$\mathrm{Na}$ região metropolitana de Maceió, as enchentes costumam ocorrer em maior frequência nos terrenos de declividade baixa, em áreas de várzeas e nos terraços flúvio-lagunares e fluviais, onde se processam as erosões antrópicas em solos gleissados. De maneira geral, as classes pertencentes aos planos temáticos de informações que foram consideradas com média (nível 3) vulnerabilidade físico-ambiental à enchentes têm sua ocorrência na maior parte da área de estudo.

Ao se analisar a Figura 6 a seguir, é possível constatar que 25,55\% das áreas foram mapeadas como sendo de média vulnerabilidade e $17,48 \%$ com muito alta (nível 5) vulnerabilidade. Já as classes consideradas com alta (nível 4), baixa (nível 2) e muito baixa (nível 1) vulnerabilidades ocupam, respectivamente, em torno de 2,94\%,7,07\% e 11,79\% da área de estudo. Embora uma parcela significativa das classes que integram os planos temáticos de informações utilizados não seja enquadrada em nenhuma faixa de vulnerabilidade, isto é, sem ocorrência (35,18\%), ainda assim as características físico-ambientais e antropogênicas das classes mapeadas possuem de média, alta e muita alta vulnerabilidade, ou seja, em torno de 45,97\% (Figura 6).

A integração dos planos temáticos de informações para delimitação das áreas vulneráveis à enchente/inundação segue o mesmo princípio metodológico utilizado no mapeamento das áreas vulneráveis ao deslizamento de terra. Os valores atribuídos a partir das características físicoambiental e socioeconômica também são capazes de indicar a propensão natural que a área possui

\begin{tabular}{llllll}
\hline Caminhos de Geografia & Uberlândia - MG & v. 19, n. 67 & Set/2018 & p. 268-288 & Página 282
\end{tabular}


em ser atingida por problemas relacionados às chuvas intensas. Portanto, a vulnerabilidade da RMM à enchentes pode variar tanto entre as classes de um mesmo plano temático de informação como entre os próprios planos. Assim sendo, analisando a Figura 7, é possível verificar que a participação relativa dos planos temáticos de informações para composição das faixas de vulnerabilidade ocorreu de forma variada. As classes que integram as unidades geomorfológicas contribuíram com $25,17 \%$ para composição das áreas consideradas como muito baixa vulnerabilidade físico-ambiental à enchentes. Já as classes de declividade consideradas como muito alta vulnerabilidade participaram $57,00 \%$ das ocorrências para composição dessa faixa de vulnerabilidade (Figura 7 ).

Ainda pela observação da Figura 7, é possível concluir que as classes que integram as unidades de solo e uso do solo tiveram uma pequena participação na composição das faixas de vulnerabilidade à enchentes. No caso das classes de solos, a maior parte foi qualificada como sem ocorrência (em torno de $83,04 \%$ ), ou seja, possuem vulnerabilidade físico-ambiental em proporção desprezíveis para a ocorrência de enchentes.

Ao contrário das classes de solo, o mapeamento das unidades geomorfológicas desempenhou um importante papel entre as variáveis físico-ambientais utilizadas para identificar as áreas propensas à enchentes. Tal fato pode ser percebido quando observada a presença do referido plano temático na composição de todas as faixas de vulnerabilidade (Figura 7), o que acentua ainda mais o papel integrador do relevo. Todavia, cabe ressaltar a relevância da integração dos demais planos temáticos na identificação da vulnerabilidade na área de estudo.

Figura 6: Distribuição percentual por faixa de vulnerabilidade à enchentes.

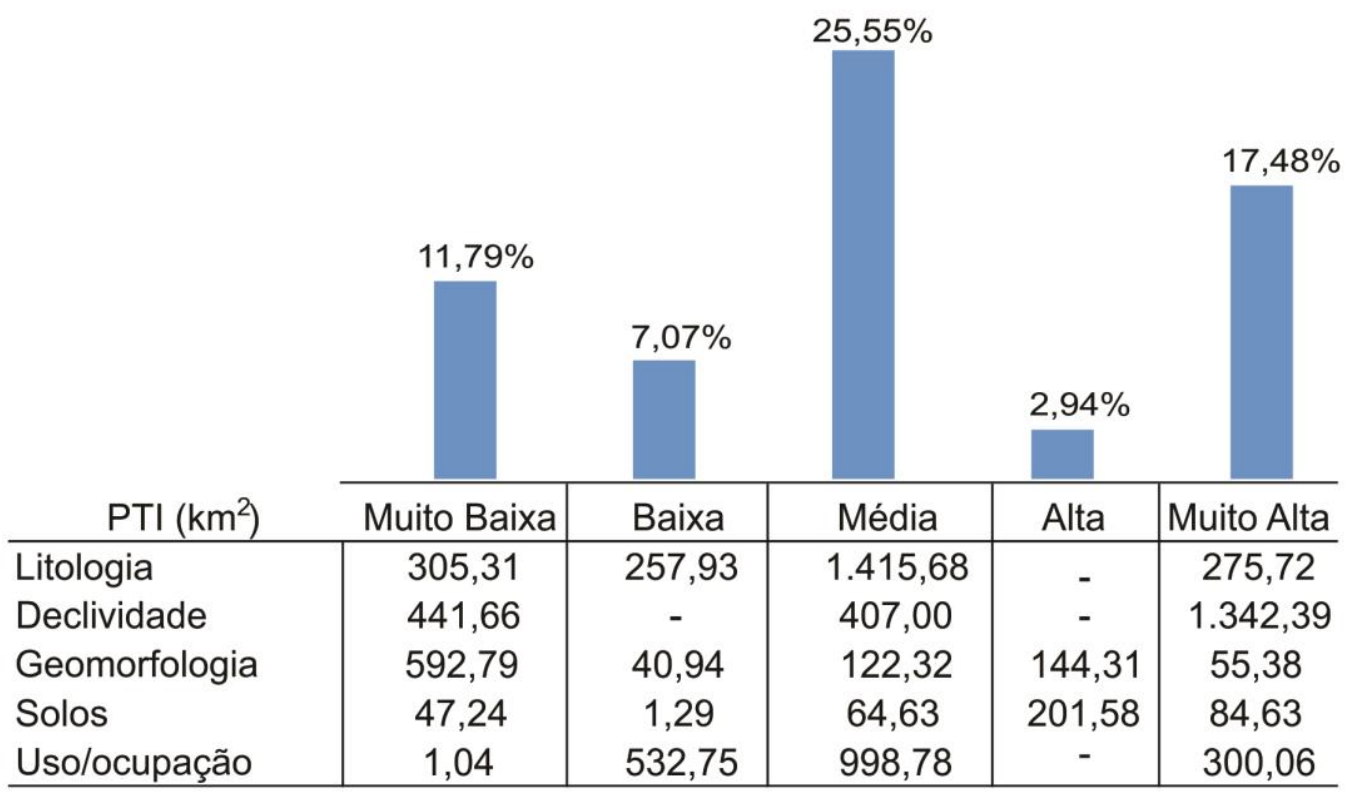

Assim sendo, a partir da análise integrada dos planos temáticos de informações, foi possível mapear as áreas propensas às ocorrências de enchentes da RMM (Figura 8). De acordo com a Tabela 4 a seguir, verificou-se que $46,44 \%\left(1.093,83 \mathrm{~km}^{2}\right)$ da referida área de estudo possuem baixa vulnerabilidade físicoambiental à enchentes. As áreas consideradas como muito alta vulnerabilidade ocupam apenas $3,67 \%$ da área de estudo. As áreas sem ocorrência representam 5,34\% e as parcelas de terras consideradas como muito baixa vulnerabilidade perfazem um total de $653 \mathrm{~km}^{2}$, isto é, ocupam uma extensão correspondente a aproximadamente $27,73 \%$ da $\mathrm{RMM}$. 
Análise da vulnerabilidade físico-ambiental causada pelas chuvas intensas na região metropolitana de Maceió
Melchior Carlos do Nascimento

Magda Adelaide Lombardo Sinval Autran Mendes Guimarães Júnior Esdras de Lima Andrade

Figura 7: Distribuição percentual por faixa de vulnerabilidade à enchentes das classes pertencentes aos PTI físico-ambiental e socioeconômico.

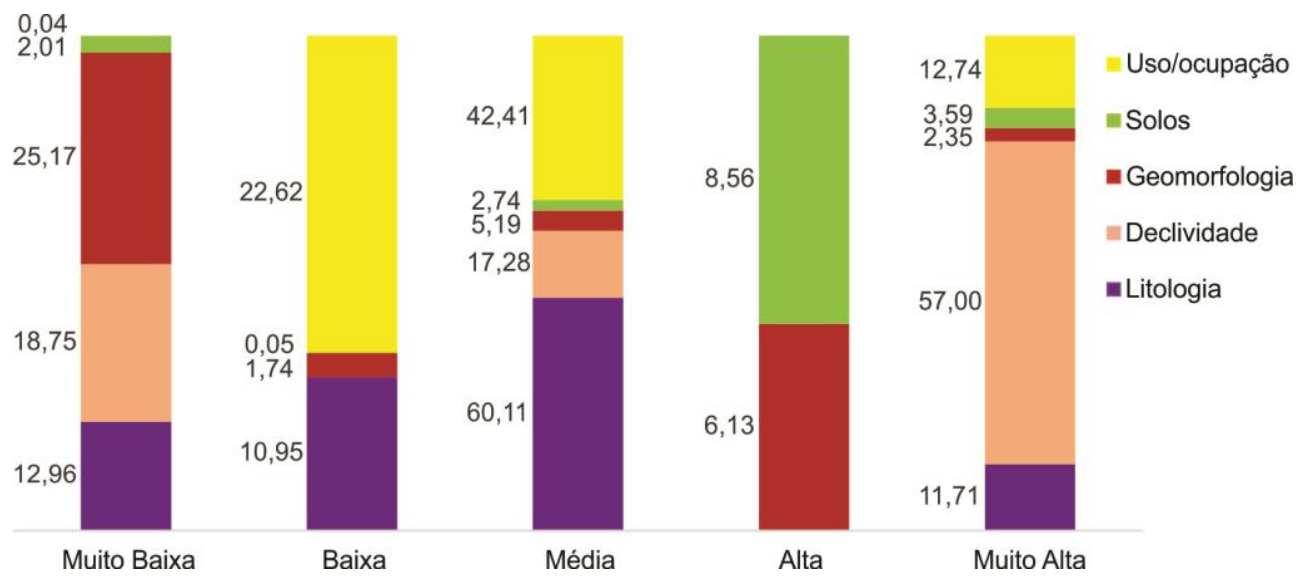

Figura 8: Distribuição espacial das áreas com vulnerabilidade físico-ambiental a enchentes na RMM, Alagoas, Brasil

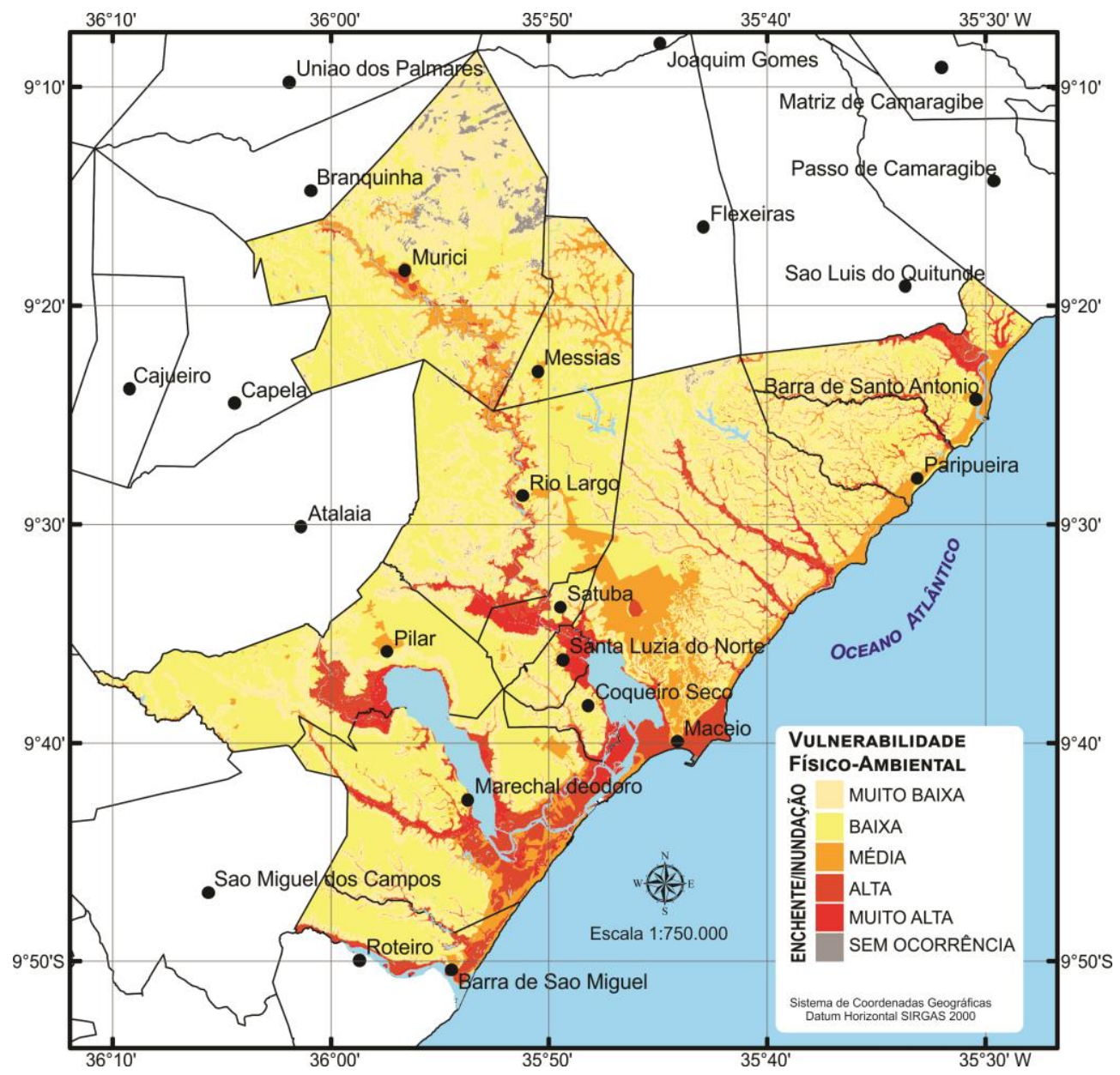


Ao se analisar a vulnerabilidade físico-ambiental à enchentes entre os municípios metropolitanos, constatou-se que as cidades de Murici e Rio Largo mesmo tendo históricos recorrentes de enchentes, sendo a última em 2010, apresentaram os maiores quantitativos de áreas consideradas como baixa vulnerabilidade, respectivamente, $185,79 \mathrm{~km}^{2}$ e $176,99 \mathrm{~km}^{2}$ (Tabela 4). Esses dois municípios juntamente a Maceió também são responsáveis por $63,33 \%\left(413,15 \mathrm{~km}^{2}\right)$ do total da área da RMM consideradas como muito baixa vulnerabilidade físico-ambiental à enchentes (Tabela 5).

A integração dos planos temáticos de informações revelou que os municípios de Messias e Murici não possuem áreas com muito alta vulnerabilidade físico-ambiental à enchente/inundação. Tal fato pode estar associado às limitações da base de dados cartográfica, utilizada em termos de escala, especialmente na parcela da área correspondente ao município de Murici. Isso não significa que no caso específico de Murici, que já possui registradas em seu histórico diversas ocorrências de enchentes e/ou inundações, a inexistência dessas áreas consideradas como muito alta vulnerabilidade reduz a insegurança iminentemente presente entre as demais faixas de vulnerabilidade.

Tabela 4: Área total das faixas de vulnerabilidade físico-ambiental à enchentes da RMM.

\begin{tabular}{ccc}
\hline Vulnerabilidade à Enchentes & $\mathbf{k m}^{\mathbf{2}}$ & $\%$ \\
\hline Sem Ocorrência & 125,68 & 5,34 \\
Muito Baixa & 653,00 & 27,73 \\
Baixa & $1.093,83$ & 46,44 \\
Média & 243,01 & 10,32 \\
Alta & 153,31 & 6,51 \\
Muito Alta & 86,38 & 3,67 \\
\hline
\end{tabular}

Tabela 5: Área total das faixas de vulnerabilidade físico-ambiental à enchentes entre os municípios que integram a RMM, Alagoas, Brasil.

\begin{tabular}{l|c|c|c|c|c}
\hline \multirow{2}{*}{\multicolumn{1}{c|}{ Município }} & \multicolumn{5}{c}{ Área $\left.\mathbf{( k m}^{2}\right)$} \\
\cline { 2 - 6 } & Muito Baixa & Baixa & Média & Alta & Muito Alta \\
\hline Barra de Santo Antônio & 43,31 & 56,25 & 17,39 & 8,76 & 10,03 \\
Barra de São Miguel & 11,00 & 38,56 & 7,36 & 11,94 & 4,68 \\
Coqueiro Seco & 7,51 & 14,73 & 1,40 & 1,59 & 4,07 \\
Maceió & 154,40 & 175,63 & 92,21 & 39,61 & 17,19 \\
Marechal Deodoro & 47,54 & 154,93 & 29,57 & 46,37 & 20,49 \\
Messias & 37,34 & 54,16 & 18,77 & 1,13 & - \\
Murici & 176,85 & 185,79 & 35,29 & 5,79 & - \\
Paripueira & 36,39 & 49,67 & 12,18 & 3,92 & 1,31 \\
Pilar & 43,17 & 158,70 & 6,42 & 14,80 & 7,89 \\
Rio Largo & 82,31 & 176,99 & 19,17 & 13,71 & 5,51 \\
Santa Luzia do Norte & 7,14 & 11,09 & 1,70 & 1,79 & 6,86 \\
Satuba & 6,05 & 17,32 & 1,56 & 3,91 & 8,32 \\
\hline
\end{tabular}

Dentre os municípios da RMM que possuem áreas consideradas como muito alta vulnerabilidade, as cidades de Marechal Deodoro, Maceió e Barra de Santo reúnem as maiores extensões de terras com muito alta vulnerabilidade à enchentes, respectivamente $20,49 \mathrm{~km}^{2}, 17,19 \mathrm{~km}^{2}$ e $10,03 \mathrm{~km}^{2}$. 


\section{CONSIDERAÇÕES FINAIS}

A conjugação dos fatores físicos naturais, os quais, por sua vez, influenciam as características de relevo e os tipos de modelados predominantes na RMM e os sistemas de usos e ocupação foram considerados decisivos para o mapeamento das áreas propensas aos deslizamentos de terra e enchentes. No caso dos aspectos físico-ambientais, pode-se admitir que a RMM apresenta domínio de ambientes formado pelos modelados de acumulação e dissecação, no qual predominam os processos erosivos sobre os processos de alteração e de acréscimo de materiais superficiais. De maneira geral, essas instabilidades correspondem às áreas atingidas pelas atividades humanas e àquelas em que as condições do relevo e do clima atuam de maneira mais intensa.

Os modelados de acumulação, em geral constituídos principalmente por sedimentos arenosos, arenoargilosos e argilosos, encontram-se cobertos por vegetação descontínua de coco-da-baía associado às formações flúvio-marinhas (mangues). Além destas ocorrências, também são encontrados nos modelados de acumulação adensamentos populacionais, nos quais os processos predominantes correspondem enchentes, isto é, às cheias periódicas e à ação das águas de inundação, ambos provocados pelas variações dos regimes hidrológicos e das chuvas.

No caso dos modelados de dissecação, caracterizado por ambientes instáveis, formados por vales fluviais com amplitudes variáveis, estreitos, eventualmente preenchidos de materiais, sobre rochas intemperizadas, nos quais são encontrados os remanescentes florestais, as lavouras da cana-deaçúcar e aglomerações populacionais. Do ponto de vista físico-ambiental, os processos dominantes correspondem, entre outros, aos deslizamentos de terra (movimentos de massa), especialmente durante os períodos de maior intensidade pluviométrica.

Considerando tais dinâmicas e a partir da análise integrada das variáveis geomorfológicas, pedológicas, litológicas, declividade e das formas predominantes de uso e cobertura vegetal, foi possível delimitar na RMM os diferentes níveis de vulnerabilidade físico-ambiental aos eventos relacionados aos deslizamentos de terra e enchentes. Portanto, utilizando técnicas de geoprocessamento, observou-se que cerca de $22,66 \%$ e $17,48 \%$ da RMM possui muito alta (nível 5) vulnerabilidade físico-ambiental, respectivamente a deslizamento de terra e enchentes. Todavia, apesar da maior parte da RMM ter sido delimitada como áreas com muito baixa (nível 1) vulnerabilidade físico-ambiental a deslizamento de terra e enchentes, respectivamente $26,18 \%$ e $25,55 \%$, mesmo que em porção inferior, as áreas mapeadas com alta (nível 4) e muita alta (nível 5) vulnerabilidade físico-ambiental, quando da ocorrência de chuvas intensas, às populações atingidas sofrem diversos prejuízos econômicos e sociais, fato esse que evidencia a necessidade da atuação do poder público local na perspectiva de fortalecer os mecanismos de controle e gestão preventiva, especialmente aqueles relacionados aos fatores inerentes ao desenvolvimento urbano.

Assim sendo, observou-se que as atividades agropecuárias ocupam uma extensão de 1.400,13 Km2 $(59,45 \%)$, portanto, sendo responsáveis pelas principais alterações na paisagem da área de estudo. Ainda em relação aos sistemas de uso predominante, os resultados indicam que a maior parte da RMM está ocupada por classes mapeadas com média vulnerabilidade aos deslizamentos de terra e enchentes, respectivamente $1.362,95 \mathrm{Km} 2(64,21 \%)$ e $985,14 \mathrm{Km} 2(54,06 \%)$. Para finalizar, pode-se admitir que os resultados alcançados podem subsidiar tecnicamente os gestores, oferecendo informações elementares para desenvolvimento de programas preventivos de controle dos problemas advindos das chuvas intensas na RMM.

\section{REFERÊNCIAS}

ALAGOAS. SEPLAN/CDCT/NMRH - Núcleo de Meteorologia e Recursos Hídricos. Relatório da Análise Climática do Estado de Alagoas (Coord. ABREU, R. de A), 1999, 31f. Mimeografado.

ALAGOAS. IMA/AL. Cobertura vegetal do estado de Alagoas \& mangues de Alagoas. (Coord. Afrânio Farias de Menezes). Maceió: IMA/AL; Petrobrás, 2010, 202p.

ALMEIDA, L. D. Suscetibilidade: novo sentido para a vulnerabilidade. Revista Bioética. v. 18, n. 3, p. 537 - 548. 2010.

ANDRADE, M. C. Usinas e Destilarias em Alagoas. Maceió: EDUFAL, 2. ed., v. 1, 140 p. 2010.

ASSIS, J. S.; ALVES, A. L.; NASCIMENTO, M. C. Atlas Escolar de Alagoas - Estudo GeoHistórico e Cultural. 2 ed. João Pessoa: Grafset, 216 p. 2012.

\begin{tabular}{llllll}
\hline Caminhos de Geografia & Uberlândia - MG & v. 19, n. 67 & Set/2018 & p. 268-288 & Página 286
\end{tabular}


ASSIS, J. S. Biogeografia e conservação da biodiversidade - projeções para Alagoas. Maceió: Catavento, 2000. 200p.

A vegetação dos tabuleiros costeiros alagoanos: caracterização e zoneamento geoambiental. Relatório Técnico: Convênio Universidade Federal de Alagoas; Empresa Brasileira de Pesquisa Agropecuária. Maceió-Aracaju, 54 p., 1999.

Um projeto de Unidades de Conservação para o Estado de Alagoas. Rio Claro: IGCE/UNESP, 1998. Tese (Doutorado em Geografia - Organização do Espaço). IGCE/UNESP, 1998. $241 \mathrm{p}$.

Distribuição da vegetação natural e antrópica na Região Nordeste. Boletim de Geografia Teorética. Rio Claro, v. 15, p. 337-347, 1985.

BIREME. Biblioteca Virtual de Saúde. Disponível em: http://www.bireme.br/php/index.php. Acesso realizado em: 02 de março de 2015.

EMBRAPA, Empresa Brasileira de Pesquisa Agropecuária. Zoneamento Agroecológico do Estado de Alagoas - Levantamento de Reconhecimento de Baixa e Média Intensidade dos Solos do Estado de Alagoas. Recife: Embrapa Solos, 2012, 238p. 1 DVD-ROM (Relatório Técnico).

BRASIL. Ministério da Integração Nacional. Diretoria de Defesa Civil. Política Nacional de Defesa Civil. 2007, 85 p.

CHRISTOFOLETTI, A. Geomorfologia. 2. ed. São Paulo: Edgard Blücher, 188p. 1980.

COSTA, J. A. A. Geomorfologias da área de Maceió. Dissertação de Mestrado. Programa de PósGraduação em Geografia, UFBA, Salvador-BA, 133 p. 1980.

CREPANI, E.; MEDEIROS, J. S.; HERNANDEZ FILHO, P.; FLORENZANO, T. G.; DUARTE, V.; BARBOSA, C. C. F. Sensoriamento remoto e geoprocessamento aplicados ao zoneamento ecológico-econômico e ao ordenamento territorial. Instituto Nacional de Pesquisas Espaciais INPE, Santa Maria-RS, 103 p. 2001.

CUTTER S. L. Vulnerability to environmental hazards. Progress in Human Geography, v. 20, n. 4, p.529-539, Dec. 1996. https://doi.org/10.1177/030913259602000407

DANTAS, J. R. A.; CALHEIROS, M. E. V. Estratigrafia e geotectônica. In: BRASIL - DNPM. Mapa geológico do Estado de Alagoas: texto explicativo. Recife: DNPM, 1986. p.7-50.

FEIJÓ, F. J. Bacia de Sergipe Alagoas. Rio de Janeiro. Geociências: Revista da PETROBRÁS, Rio de Janeiro, 8(1): 149 - 161, jan./mar., 1994.

FONSECA, A. L. B. de AZEVEDO, L. M. P. Climatologia. In: BRASIL, Ministério das Minas e Energia, Secretaria Geral, Projeto Radambrasil. Folhas SC. 24/25 Aracaju/Recife. Rio de Janeiro: PROJETO RADAMBRASIL, 1983 p. 812-837 (Série: LRN. V. 30).

GOES, M. H. de B. Ambientes Costeiros do Estado de Alagoas. 3 v. Rio de Janeiro, 1979, $397 \mathrm{f}$.

Dissertação (Mestrado em Geografia) - Universidade Federal do Rio de Janeiro, 1979.

IBGE, Instituto Brasileiro de Geografia e Estatística. Censo 2010. Disponível em: <www.ibge.gov.br> Acesso em: 25 de novembro de 2013.

IBGE, Instituto de Geografia e Estatística. Cartas Topográgicas. Folhas: Atalaia (SC-24-X-D-VI-2), Rio Largo (SC-25-V-C-I-3) e Viçosa (SC-24-X-D-III-4), 1:50.000. 1987.

JACOMINE, P. K. T. et al. Levantamento exploratório-reconhecimento de solos do Estado de Alagoas. Recife: EMBRAPA/SUDENE, 1975. 532 p. (Boletim Técnico, 35).

JULIÃO, R. P.; NERY, F.; RIBEIRO, J. L.; BRANCO, M. C.; ZÊRERE, J. L. Guia Metodológico para a Produção de Cartografia Municipal de Risco e para a Criação de Sistemas de Informação Geográfica (SIG) de Base Municipal. Lisboa: Autoridade Nacional de Protecção Civil / Instituto Geográfico Português, 2009, $93 \mathrm{p}$.

LIMA, I. F. Maceió a cidade restinga: contribuição ao estudo geomorfológico do litoral alagoano. 2 ed. Maceió: Edufal, 1990. 255p.

LIMA, E. Q.; AMARAL, R. F. Vulnerabilidade da zona costeira de Pititinga/RN, Brasil. Revista Mercator, Fortaleza, v. 12, n. 28, p. 141-153, 2013. https://doi.org/10.4215/RM2013.1228.0010

$\begin{array}{llllll}\text { Caminhos de Geografia } & \text { Uberlândia - MG } & \text { v. 19, n. } 67 & \text { Set/2018 } & \text { p. 268-288 } & \text { Página } 287\end{array}$


LOPES, P. S. P. R. Avaliação Regional da Susceptibilidade a Deslizamentos no Concellho de Satarém. Dissertação de Mestrado. 2007. Programa de Pós-raduação em Geografia - Universidade de Lisboa. Lisboa-Portugal, 120 p., 2008.

MARQUES, R. C. C. Geomorfologia e evolução da região costeira do Complexo EstuarinoLagunar Mundaú-Manguaba. Rio de Janeiro, 1987, 151 f. Tese (Mestrado em Geografia) Universidade Federal do Rio de Janeiro, 1987.

MEDEIROS, M. D.; PEREIRA, V. H. C.; ALMEIDA, L. Q. Áreas de Vulnerabilidade Ambiental na zona oeste de Natal/ RN/ Brasil. Revista Geonorte, Edição Especial, v. 1, n. 4, p.474 - 486, 2012.

NOU, E.A.V.; BEZERRA, L.M.M.; DANTAS, M. Geomorfologia. In: Brasil, Ministério das Minas e Energia, Secretaria Geral, Projeto Radambrasil. Folhas SC. 24/25 Aracaju/Recife. Rio de Janeiro: DIPUB/RADAMBRASIL, 1983. p. 347-443 (Série: LRN. V. 30).

PETROBRAS. Cartas Topográficas. Folhas: 631-1-1, 631-1-2, 630-2-3, 631-1-4, 631-1-3, 630-3-1, 630-3-2, 631-4-1, 630-3-4 e 630-3-3, 1:25.000. 1965.

RESENDE, M.; NILTON, C. REZENDE, S. B.; CORRÊA, G. F. Pedologia: base para distinção de ambientes. Viçosa: NEPUT, 4 ed, 338 p. 2002.

RICTHER, A. J. et al. Cartas geológicas da Bacia Sedimentar Sergipe - Alagoas: textos das legendas. In: MME/DNPM. Cartas Geológicas da Bacia Sedimentar Sergipe - Alagoas: - Folhas: Rio Largo (SC.25-V-C-I-3) São Luís do Quitunde (SC.25-V-C-I-4), Marechal Deodoro (SC.25-V-C-IV-1) e Maceió (SC.25-V-C-IV-2): 1975. Recife, 1975.

ROSS, J. L. S. Geomorfologia: Ambiente e Planejamento. São Paulo: Contexto, 2. ed. 85 p., 1991.

SILVEIRA, A. F.; BUENO, L. M. M. Sustentabilidade e Vivências em uma Bacia Hidrográfica Urbana: resultados de intervenções recentes, Campinas/SP, Brasil. Encuentro de Geógrafos de América Latina, Perú, p. 1-18, 2013.

SUDENE, Superintendencia do Desenvolvimento do Nordeste. Carta Topográfica. Folha Rio Largo (SC-25-V-C-I), 1:100.000. 1985.

TROPPMAIR, H. A. Metodologia simples para pesquisar o meio ambiente. Rio Claro: 1988, 232 p.

VARNES, D. J. and IAEG. Commission on Landslides and other Mass-Movements: Landslide hazard zonation: a review of principles and practice, UNESCO Press, Paris, 63 p., 1984.

VELOSO, H. P.; GÓES FILHO, L. Fitogeografia brasileira: classificação fisionômica-ecológica da vegetação neotropical. In: Ministério das Minas e Energia, Petróleo Brasileiro s. a., Departamento Nacional de Produção Mineral, 1982, Salvador. (Bol. Técnico. Série Vegetação, 1).

VELOSO, H. P.; RANGEL FILHO, A. L. R. e ALVES LIMA, J. C. Classificação da vegetação brasileira, adaptada ao sistema universal. Rio de Janeiro: IBGE, 1991. 124 p.

WAKE. M.; VIANA, C.D.B.; SOUZA, C.G. Pedologia: levantamento exploratório de solos. In: Brasil, Ministério das Minas e Energia, Secretaria Geral, Projeto Radambrasil. Folhas SC. 24/25

Aracaju/Recife. Rio de Janeiro: DIPUB/RADAMBRASIL, 1983. p. 445-572 (Série: LRN. V. 30).

Recebido em: 04/07/2017

Aceito para publicação em: 25/04/2018 